\title{
The Neomuran Revolution and Phagotrophic Origin of Eukaryotes and Cilia in the Light of Intracellular Coevolution and a Revised Tree of Life
}

\author{
Thomas Cavalier-Smith \\ Department of Zoology, University of Oxford, Oxford OX1 3PS, United Kingdom \\ Correspondence: tom.cavalier-smith@zoo.ox.ac.uk
}

Three kinds of cells exist with increasingly complex membrane-protein targeting: Unibacteria (Archaebacteria, Posibacteria) with one cytoplasmic membrane (CM); Negibacteria with a two-membrane envelope (inner $\mathrm{CM}$; outer membrane [OM]); eukaryotes with a plasma membrane and topologically distinct endomembranes and peroxisomes. I combine evidence from multigene trees, palaeontology, and cell biology to show that eukaryotes and archaebacteria are sisters, forming the clade neomura that evolved $\sim 1.2$ Gy ago from a posibacterium, whose DNA segregation and cell division were destabilized by murein wall loss and rescued by the evolving novel neomuran endoskeleton, histones, cytokinesis, and glycoproteins. Phagotrophy then induced coevolving serial major changes making eukaryote cells, culminating in two dissimilar cilia via a novel gliding-fishing-swimming scenario. I transfer Chloroflexi to Posibacteria, root the universal tree between them and Heliobacteria, and argue that Negibacteria are a clade whose OM, evolving in a green posibacterium, was never lost.

\section{THE FIVE KINDS OF CELLS}

$\mathrm{T}^{\mathrm{h}}$ he eukaryotic cell originated by the most complex set of evolutionary changes since life began: eukaryogenesis. Their complexity and mechanistic difficulty explain why eukaryotes evolved 2 billion years or more after prokaryotes (Cavalier-Smith 2006a). To understand these changes, we must consider the cell biology of all five major kinds of cells (Fig. 1); determine their correct phylogenetic relationships; and explain the causes, steps, and detailed mechanisms of the radical transitions between them. Figure 1 highlights three fundamentally different kinds of prokaryote differing greatly in membrane topology and membrane and wall chemistry. In all cells, the major membrane lipids are glycerophospholipids having two hydrophobic hydrocarbon tails attached to a hydrophilic phosphorylated glycerol head, but glycerol-phosphate stereochemistry differs in archaebacteria ( $s n$-glycerol-1-phosphate) from that in all other cells (sn-glycerol-3-phosphate). Negibacteria and posibacteria (collectively called

Editors: Patrick J. Keeling and Eugene V. Koonin

Additional Perspectives on The Origin and Evolution of Eukaryotes available at www.cshperspectives.org.

Copyright (C) 2014 Cold Spring Harbor Laboratory Press; all rights reserved; doi: 10.1101/cshperspect.a016006

Cite this article as Cold Spring Harb Perspect Biol 2014;6:a016006 
T. Cavalier-Smith
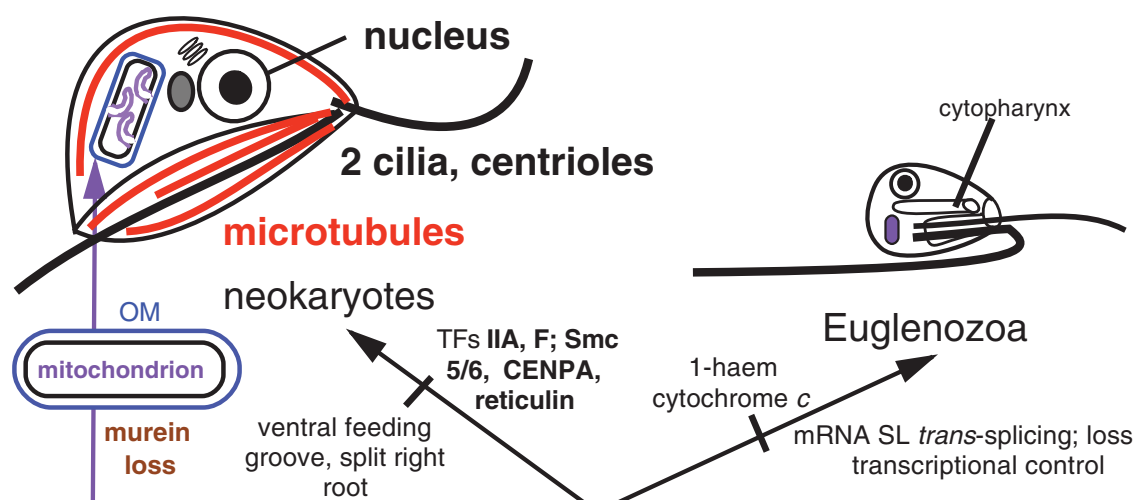

eukaryogenesis: endomembranes, peroxisomes,

endoskeleton, nucleus, centrioles, cilia, cyclins, mitosis, sex
phagotrophy $t$ type IV secretion lost $\begin{gathered}\text { BACTER } \\ \text { (=prokaryotes) }\end{gathered}$

\begin{tabular}{|c|c|}
1.2 Gy ago & $\begin{array}{l}\text { hyperthermophily: } \\
\text { isoprenoid ether } \\
\text { phospholipds; } \\
\text { reverse gyrase }\end{array}$ \\
loss of PI, ACP, CL, \\
sterols, and many genes
\end{tabular} Archaebacteria

$-\frac{\text { neomura }}{\text { neomuran }}$ revolution

$\underbrace{\text { Negibace }}_{\text {murein peptidoglycan }}$

$N$-linked glycoprotein

histones, Cdc6, MCM, PCNA;

ESCRT III GTPase; SRP arrest;

losses of Xer termination,

DnaA, G, DNA gyrase, SecA

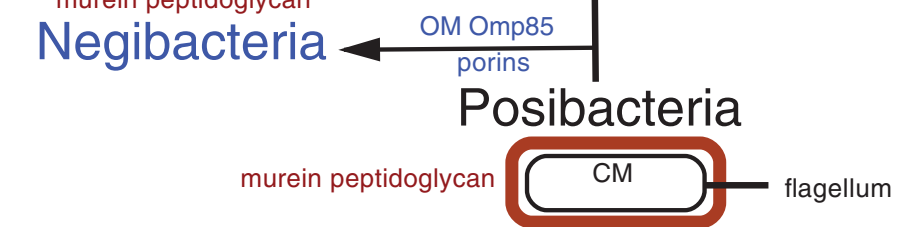

acyl ester phospholipids; SRP protein-targeting to CM ; cell division by FtsZ and divisome DnaA replication initiator; Xer DNA replication terminator; anoxygenic green bacterial photosynthesis; Smc condensins; parABS origin segregation; DNA translocases; conjugation via type IV secretion;

\subsection{Gy ago}

Figure 1. Relationships between the five major cell types, showing key evolutionary innovations in the transitions making them. Rigid murein cell walls originated before the cenancestor of all life using both D- and L-amino acids in the first cell, a posibacterium with acyl ester glycerophospholipids that divided using FtsZ, possibly a photoheterotroph similar to Heliobacterium. Negibacteria evolved by acquiring an outer membrane (OM) with complex targeting of porins and other $\beta$-barrel proteins inserted by Omp85-dependent machinery never lost in the history of life, being retained when eukaryotes enslaved phagocytosed negibacteria to make mitochondria and subsequently chloroplasts (even kept in secondarily anaerobic DNA-free hydrogenosomes and mitosomes that evolved by drastically modifying aerobic mitochondria). The neomuran revolution was arguably a stabilizing response to traumatic loss of murein. Histones H3/4 ensured passive negative DNA supercoiling (making nucleosomes) to replace eubacterial ATP-driven supercoiling by DNA gyrase; this stabler DNA coiling forced drastic coevolutionary changes in RNA polymerase and especially DNA replication machinery: repair polymerase $\delta$ replaced DNA polymerase III, the $\beta$-clamp became PCNA, the replication fork helicase Mcm replaced DnaB, the unrelated Pol primase replaced DnaG primase, and Cdc6 replaced the replication initiator DnaA; Cdc6 possibly evolved from a gene duplicate of the eubacterial clamp loader DnaX, itself undergoing minor modification to neomuran RFC. (Legend continues on following page.) 
"eubacteria") are mutually closer in cell envelope chemistry and informational machinery than either is to archaebacteria, whose basic informational machinery is eukaryote-like despite their cells being fully prokaryotic in structure and DNA segregation machinery. Eubacteria, unlike eukaryotes and archaebacteria, generally have cell walls of the peptidoglycan murein that forms a covalently cross-linked bag (sacculus) completely surrounding the cytoplasmic membrane (CM). Murein hydrolase enzymes must repeatedly cleave, and other enzymes reseal, murein covalent bonds so that eubacteria can grow without bursting under high internal osmotic pressure (Egan and Vollmer 2013).

Some derived methanogenic archaebacteria have covalently cross-linked walls of pseudomurein, a different peptidoglycan with similar cleavage-resealing growth. However, other archaebacteria and all eukaryotes have cell surfaces of non-cross-linked globular glycoproteins containing hydrophilic oligosaccharides covalently linked to asparagine (N) residues. $N$-linked glycoproteins are made cotranslationally, oligosaccharides being attached during trans-membrane protein secretion by membrane-associated ribosomes. I argued that this shared character evolved in the last common ancestor (cenancestor) of eukaryotes and archaebacteria, which jointly constitute the putative clade neomura. The neomuran theory of eukaryote origins (Cavalier-Smith 1987c; revised and updated: Cavalier-Smith 2002c, 2009, 2010c) has a phylogenetic part and a causal mechanistic part, as should any scientific explanation of megaevolutionary events. Many inadequate "theories" of eukaryote origin focus exclusively on phylogeny and have no explanatory part or only a cursory, unconvincing one. Phylogenetically, the neomuran theory asserts that (1) eubacteria are substantially older than and ancestors of neo-

Figure 1. (Continued) Novel TATA-box-binding transcription factors (TBP and others) (Ouhammouch et al. 2009) replaced the eubacterial transcription regulator CrtA. Murein loss freed MreB filaments that maintain eubacterial rod shape (or related ParM filaments that segregate some plasmids) to become the actin endoskeleton, conferring osmotic stability; new ESCRT-III filaments helped membrane division, allowing loss of FtsZ in eukaryotes and some archaebacteria. Novel cotranslationally made $N$-linked glycoprotein enabled archaebacteria to make rigid S-layer-like walls and eukaryotes a flexible cell surface coat, allowing phagotrophy and ingestion of prey cells to evolve, triggering a cascade of eukaryogenic changes associated with coated vesicle origins. These mediated endomembrane differentiation, internal digestion, targeted vesicle fusion, and nuclear envelope evolution to protect chromatin internalized by phagocytosis (see Fig. 2); $\alpha$-tubulin, $\beta$-tubulin, and $\gamma$ tubulin evolved from posibacterial plasmid-segregating TubZ GTPase, enabling DNA segregation by mitosis, drastically changing chromosome organization; cohesins enabling mitosis and eukaryotic cell-cycle controls evolved from duplicated Smc condensins. Archaebacteria replaced acyl ester lipids by heat-stable isoprenoid tetraethers to become the first extremophiles, but lost so many lipids and proteins that they could never have evolved directly into eukaryotes, as did the transient neomuran ancestor, retaining far more eubacterial characters. Archaebacteria kept fatty acid (FA) synthesis (Lombard et al. 2012a) but lost acyl-carrier protein (ACP), which enables rapid bulk FA synthesis in eubacteria and eukaryotes, no longer needed for the trace FA amounts that sufficed after archaebacteria lost acyl esters, including phosphatidylinositol (PI) and cardiolipin (CL). Neokaryotes retained bacterial transcription regulation but evolved new transcription factors (TFs). Soon after mitochondrially donated group II self-splicing introns became spliceosomal introns in the cenancestral eukaryote (Cavalier-Smith 1991c), Euglenozoa evolved trans-splicing of spliced-leader (SL) miniexons for all mRNAs (Cavalier-Smith 1993) and lost transcriptional control of gene expression. Neokaryotes alone replaced centromeric histone $\mathrm{H} 3$ by CENP-A and evolved Smc5/6 for DNA repair. Archaebacterial flagella are not homologous to, and evolved independently of, eubacterial flagella, which must have evolved in Negibacteria, probably in early Gracilicutes (Cavalier-Smith 2006c); so if the tree is correctly rooted within Posibacteria, they were presumably acquired by Posibacteria by lateral gene transfer (LGT) subsequently, but before actinobacteria diverged from Teichobacteria (see Fig. 3). Ancestral green bacteria lacked flagella but could probably glide and thus make stromatolites, yielding the oldest fossil evidence for eubacteria. Absence of photosynthetic carbon fixation in archaebacteria means that, unlike the much older eubacteria, they could never have fueled an extensive global ecosystem alone. 
mura; and (2) archaebacteria are sisters of eukaryotes, not their ancestors. This explains why eukaryotes are a blend of eubacteria-like (e.g., membrane chemistry) and archaebacteria-like characters (e.g., $N$-linked glycoproteins, information-processing machinery) plus entirely novel features (cell structure, mitosis). Eubacteria-like characters, ancestral for all life, were inherited vertically by eukaryotes, while archaebacteria secondarily evolved unique lipids; shared archaebacteria-like characters originated only in the neomuran cenancestor (last common ancestor); and uniquely eukaryotic characters evolved immediately after eukaryotes diverged from archaebacteria. No other theory explains that as simply. Assuming that archaebacteria were directly ancestral to eukaryotes (Van Valen and Maiorana 1980) requires nonparsimonious assumptions that eubacteria-like characters were regained during eukaryogenesis.

\section{PHAGOTROPHY, CYTOSKELETON, MOTORS, AND THE COEVEOLUTIONARY THEORY OF EUKARYOGENESIS}

Three key innovations made eukaryotes: (1) an internal cytoskeleton of formin-associated actin filaments cross-linked by actin-related proteins (Arp 2/3) plus microtubules ( $\alpha, \beta$-tubulin) nucleated by $\gamma$-tubulin; (2) cytoskeleton-associated molecular motor ATPases: myosin for actin; kinesin and subsequently dynein for microtubules; (3) the eukaryote-specific endomembrane system (endoplasmic reticulum [ER], Golgi complex, and lysosomes - the bags of digestive enzymes discovered by De Duve that mediate intracellular digestion in eukaryotes but no bacteria). Only subsequently could the nucleus, centrioles, mitosis, and eukaryotic genetic system evolve, using and stimulated by this novel machinery. The decisive evolutionary mediator of eukaryogenesis was the origin of phagocytosis and intracellular prey digestion for the first time in history, which also enabled uptake and transformation of an $\alpha$-proteobacterium into mitochondria, greatly improving aerobic utilization of intracellular digestion products simultaneously with the origin of the nucleus and cilia (Cavalier-Smith 2002c).
These ideas arose before archaebacteria were recognized (Woese and Fox 1977). De Duve and Wattiaux (1966) suggested that rough ER evolved by budding from the CM of a wall-less bacterium when evolving an ability to ingest other cells by a primitive version of phagocytosis, with subsequent differentiation of internalized vesicles producing the Golgi apparatus and lysosomes for more efficient internal digestion. Stanier (1970) noted that such phagotrophy, absent from all prokaryotes, must have imposed novel selective forces favoring larger cell size and increased internal complexity, providing sufficient explanation of the greater internal complexity of eukaryotic cells, especially the origin of the internal cytoskeleton. I explained how phagotrophy, by internalizing CM with attached prokaryotic chromosomes, must have disrupted bacterial cell cycles and DNA segregation even more dramatically than wall-loss, so phagotrophy imposed novel selective forces causing evolution of mitosis, meiosis, and novel genetics and chromosome organization of eukaryotes (Cavalier-Smith 1975) and much larger genomes (Cavalier-Smith 1978b). John and Whatley $(1975,1977)$ argued that mitochondria originated from endosymbiotic purple-nonsulfur bacteria (now called $\alpha$-proteobacteria).

I argued that these novel eukaryotic genetic features all evolved as coevolutionary responses to disruption of the prokaryotic cell-surface-located genetic system by the new endomembrane system, cytoskeleton, and associated motors. Moreover, the nucleus evolved by incomplete ER fusion around chromatin to protect it from shearing damage by cytoplasmic motors, and peroxisomes stemmed from subdivision and specialization of endomembranes. As mureinwall-loss necessitated osmotically and cell-cycle-stabilizing innovations, I proposed that microtubules evolved to stabilize DNA segregation by premitotic mechanisms, and actin was required for phagotrophy (not then known) and cytokinesis. I argued that actin was the primary and microtubules the next major molecular innovation enabling eukaryotes to evolve (Cavalier-Smith 1975). We now know that actin originated slightly before eukaryotes during the neomuran revolution, from MreB filaments 
that help maintain shape for rod-like eubacteria (Löwe and Amos 2009; Wickstead and Gull 2011). However, changing MreB to actin was trivial, MreB sometimes being called "bacterial actin." More radically, gene triplication made $\alpha, \beta, \gamma$-tubulins subsequently, in the eukaryote cenancestor, probably from posibacterial plasmid-segregating GTPase TubZ, rather than related FtsZ, to make spindle microtubules for mitotic DNA segregation (Cavalier-Smith 2010c).

I now suggest that the most fundamental eukaryogenic molecular innovation was the origin of formin rings (type A2) (Chalkia et al. 2008) to promote rapid actin polymerization (by encircling the filaments' fast-growing barbed ends, drawing in monomers from profilin complexes) to extend pseudopodia around prey cells during phagotrophy, plus profilin to bind G-actin as a soluble store allowing sudden F-actin extension through formin-binding. Secondarily, actin duplicated, yielding Arp2/3 for branching by linking pointed ends to other actin filaments; with actin-capping proteins for barbed ends, branching made an osmotically stabilizing three-dimensional (3D)-gel meshwork. Figure 2 updates the intracellular coevolutionary consequences of phagotrophy. Like single-headed myosin I, actin proved essential for phagocytosis, but its involvement in cytokinesis in the contractile ring of podiate eukaryotes probably resulted from much later evolution of two-headed myosin II in early podiates (Fig. 3). Originally, eukaryote cytokinesis used the membrane-bending dynamin GTPase that evolved in the ancestral eubacterium (lost by crenarchaeotes) plus ESCRT-III GTPase filaments for membrane scission, which arguably evolved in the ancestral neomuran (CavalierSmith 2010c); crenarchaeotes lost ESCRT (and most lost FtsZ).

This coevolutionary phagotrophy theory of eukaryogenesis, enunciated before evidence for symbiogenetic origins of chloroplasts and mitochondria became compelling (Gray and Doolittle 1982; Gray 1992; Cavalier-Smith 2013b), initially wrongly assumed cyanobacterial ancestry of the whole eukaryotic cell (Cavalier-Smith 1975). I did not then appreciate the doubleness of the negibacterial envelope and likely mecha- nistic impossibility of evolving unimembranous eukaryotes by wall-loss from any negibacterium. Although that defective phylogeny is consigned to history, the central logic of phagotrophy being the driving force behind the origin of endomembranes and cytoskeleton and of the radically transformative consequences of both novelties for eukaryotic cell cycles and genetics was almost certainly correct, providing the only logically coherent explanation for eukaryogenesis that is both mechanistically and selectively convincing.

Initially I argued that centrioles and cilia evolved from microtubules substantially after the first eukaryotes (Cavalier-Smith 1975, 1978a, 1981, 1982), but that was wrong. Almost certainly the first ciliated eukaryote had one cilium only (Cavalier-Smith 1975, 1978a), but the assumption that some primitively uniciliate eukaryotes still survive (Cavalier-Smith 1987c, 2002c) was wrong. Probably all uniciliates are secondarily simplified, and the eukaryote cenancestor had two centrioles bearing dissimilar cilia, which take two cell cycles to develop to maturity, the anterior cilium being younger and forming in the first cell cycle, the older posterior one being modified in structure, position, and roots in the second cell cycle (ciliary transformation: Brugerolle 1992; Cavalier-Smith and Karpov 2012; Cavalier-Smith 2013a). Before each cell division, two new centrioles assemble beside old ones at the beginning of S phase when DNA is replicated, this being controlled by cyclin proteins unique to eukaryotes. Cyclins share a helical domain with the neomuran transcription factor TFIIb and perhaps evolved from it.

Proteolysis of proteins connecting the two older cilium-bearing centrioles allows their separation to opposite spindle poles during mitotic prophase. Possibly parent centrioles are held together by the same loop-like cohesin proteins as sister chromatids (Nasmyth 2011; Eichinger et al. 2013), both assembling at S-phase onset, and both cleaved by the enzyme separase, emphasizing the deep coevolution of chromosome and centriole cycles. However, in Drosophila at least, cohesin cleavage is inessential for centriole disengagement, which requires a drop in cyclin- 
T. Cavalier-Smith

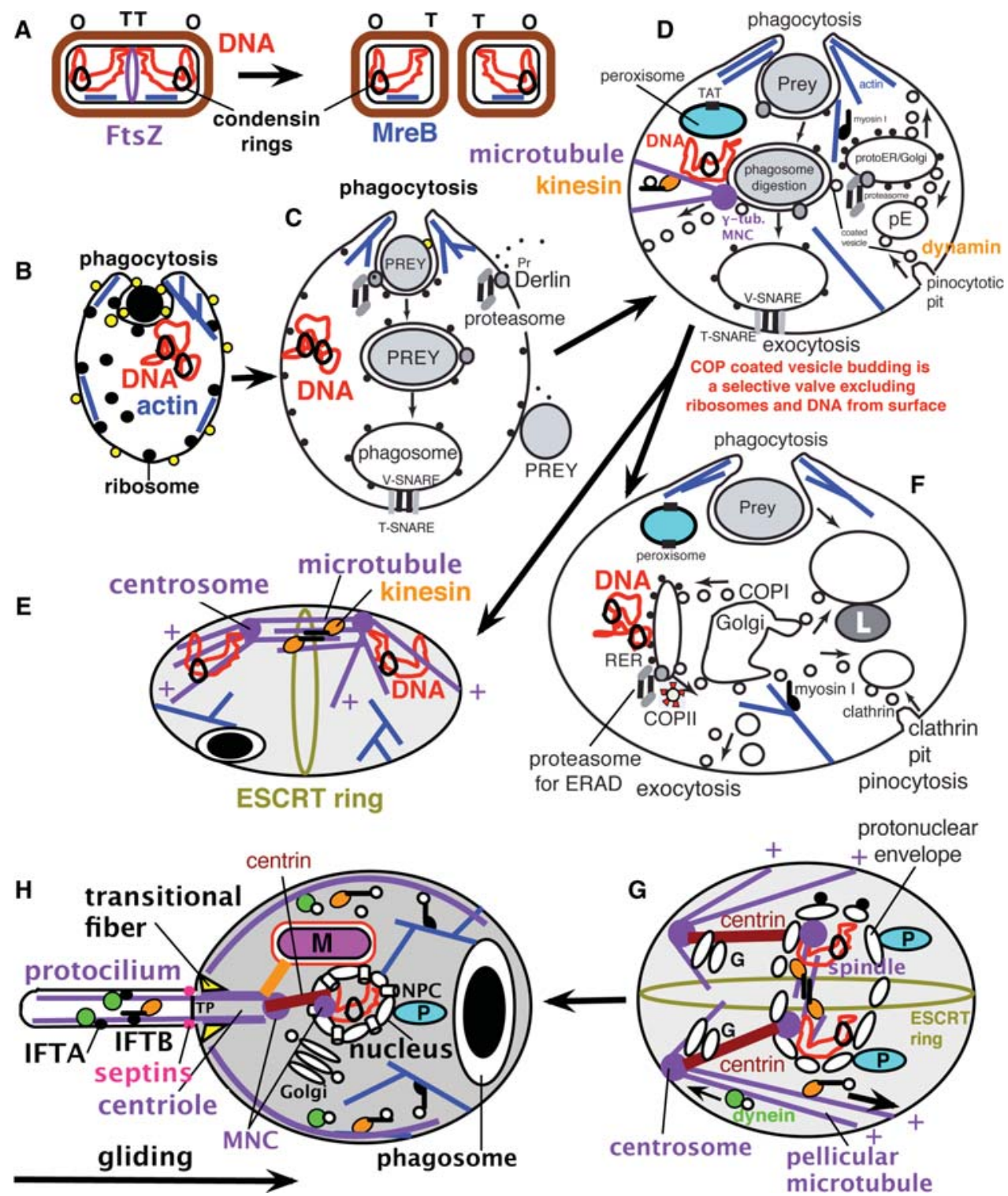

Figure 2. Intracellular coevolution during phagotrophy-driven eukaryogenesis. (A) Eubacteria segregate DNA by actively moving replicon origins $(\mathrm{O})$ by ParABS machinery, DNA condensation by Smc condensin rings, and moving termini ( $\mathrm{T}$ ) by the DNA translocase FtsK anchored at the mid-cell nascent division site, marked by the GTPase FtsZ ring for membrane scission by the divisome after XerCD recombinase resolves daughter DNAs into covalently separate molecules. Neomuran loss of murein disrupted orderly linear arrangement of chromosome origins and termini on a rigid wall, causing FtsK loss and allowing replicon numbers per chromosome to increase, and ESCRT-III GTPase filaments replaced the eubacterial divisome; simultaneously, the posibacterial paracrystalline S layer became novel $N$-linked glycoproteins. (B) In eukaryotes only, these glycoproteins (yellow) became flexible and specialized for binding prey, initially digested by enzymes secreted externally by membraneattached ribosomes. MreB (or its plasmid segregation ParM relative) (Yutin et al. 2009) evolved into actin, yielding linear filaments stimulated by formins for extending cytoplasm partly around prey, thereby increasing digestion product absorption, and duplications yielded Arp2/3, generating an osmotically stabilizing branching endoskeleton (blue). (Legend continues on following page.) 
The Neomuran Revolution and Origin of Eukaryotes

dependent kinase activity, and another centrosomal separase target may be the crucial linker of new and old centrioles (Oliveira and $\mathrm{Na}$ smyth 2013); in Caenorhabditis, cohesin seems involved only in certain developmental stages (Cabral et al. 2013). In mammals, the giant coiled-coil kendrin is a separase target mediating centriole disengagement (Matsuo et al. 2012), but its sequence is highly conserved only in vertebrates, which have a clearly related family of A-kinase anchor proteins important for many aspects of cell structure; but as neither is reliably traceable beyond vertebrates, it is possible that when early animals expanded centrosome size cleavage of more than one, possibly novel centrosome protein became necessary, even if cohesin may have been the ancestral target (still a conjecture). Cohesin rings comprise Y-shaped Smcs and kleisin cross-linkers that evolved (after pre-eukaryotes diverged from archaebacteria)

Figure 2. (Continued) $(C)$ Evolution of a surface membrane protein channel (Derlin) enabled partially digested proteins to be pulled across the membrane and fully digested on its cytosolic face by cylindrical proteasomes. Digestion products of prey completely internalized into a phagosome (center) was most efficiently absorbed; phagosome-associated V-SNAREs and CM-associated T-SNAREs evolved to refuse phagosome membranes with the surface. $(D)$ Accidental phagocytic internalization of membrane-attached DNA was made permanent by evolving COP-coated vesicles that returned membrane only to the cell surface; after exclusion of ribosomes and DNA from COP vesicles, continued phagocytosis removed all from the plasma membrane, and the internalized ribosome/DNA-associated membrane became protoER. Membrane fragmentations generated separate compartments specializing in $\beta$-oxidation of fatty acids (peroxisomes) and cytochrome P450 oxidation of aromatics and protein secretion (ER). Bacterial Sec61/SRP for extruding unfolded proteins was retained by ER and TAT machinery for unfolded proteins modified for peroxisome biogenesis (for more details, see Cavalier-Smith 2009). FtsZ-related posibacterial plasmid-segregated TubZ GTPase evolved by gene duplication into eukaryotic mitotic segregator $(\alpha$-, $\beta$-tubulin microtubules, nucleated at minus ends by $\gamma$-tubulin-containing centrosomes), microtubule rigidity mechanistically replacing peptidoglycan rigidity. Initially, microtubule polymerization forced sister centrosomes and associated DNA apart. COPs were also used for pinocytosis, and preexisting dynamin and ESCRT-III coopted for membrane scission generating protoendosomes (pE). Singlehead myosin I and kinesin diverged from a common posibacterial ATPase ancestor to form motors for internalizing phagosomes along actin filaments or minus-to-plus movement of vesicles on microtubules for exocytosis, respectively. $(E)$ Kinesin was coopted to push apart antiparallel microtubules from sister centrosomes, improving segregation, cytokinesis being by preexisting neomuran ESCRT-III GTPase ring orthogonal to the spindle. $(F)$ Simultaneously, coordinate gene duplications of COP proteins and SNAREs multiplied the number of topologically and chemically distinct compartments developmentally interlinked by vesicle transport: copII for ER to Golgi, CopI for recycling membrane from Golgi, and clathrin for making protoendosomes ( $\mathrm{pE}$ ) and lysosomes (L) (Faini et al. 2013). ( $E$ and $F$ ) Aspects of the same stage. $(G)$ A protonuclear envelope formed by partial ER cisternal fusion onto the surface of chromatin, centrosomes duplicating into centrin-connected distinct microtubule-nucleating centers (MNC) for cell-surface cortical microtubules and nuclear-envelopeassociated spindle poles. COPII coats were retained by the protonuclear envelope, evolving into nuclear pore complexes (NPC: their origin and that of importin- and RanGTP-gradient-based nucleocytoplasmic protein import using nuclear localization signals [NLS] were fully explained in Cavalier-Smith 2010c). Novel rapid DNA segregation by mitosis in anaphase replaced two-stage rigid-wall-associated prokaryotic segregation via new spindle kinesins, causing chromosome linearization and telomeres. Minus-end-directed dynein ATPase motors evolved to move vesicles along microtubules to centrosomes, fusing to form centrosome-attached, stacked Golgi cisternae $(G)$ specializing in subsequent glycosylation stages. $(H)$ Transition fibers attached a ring of microtubules to the cell surface forming a protocilium, a novel heterotrimeric kinesin-2 evolving to move them relative to protociliary membrane glycoproteins adhering to the substratum, initiating protociliary gliding to carry cells to fresh prey; recruitment of septins to the protociliary base and evolution of a transition zone plate (TP) and collar, plus anterograde (IFTB) and retrograde (IFTA) transport particles from COPI coats, and modification of nuclear protein-targeting machinery for ciliary protein import established a discrete protociliary compartment. Figure 5 shows how this could have evolved into $9+2$ cilia in the cenancestral eukaryote. Division of labor among coevolving peroxisomes ( $\mathrm{P}$, ancestrally attached to and segregated with the nuclear envelope in closed mitosis), endomembranes, and mitochondria ( $\mathrm{M}$ : derived from phagocytosed, undigested $\alpha$-proteobacteria) optimized aerobic metabolic utilization of phagotrophy digestion products. 
T. Cavalier-Smith

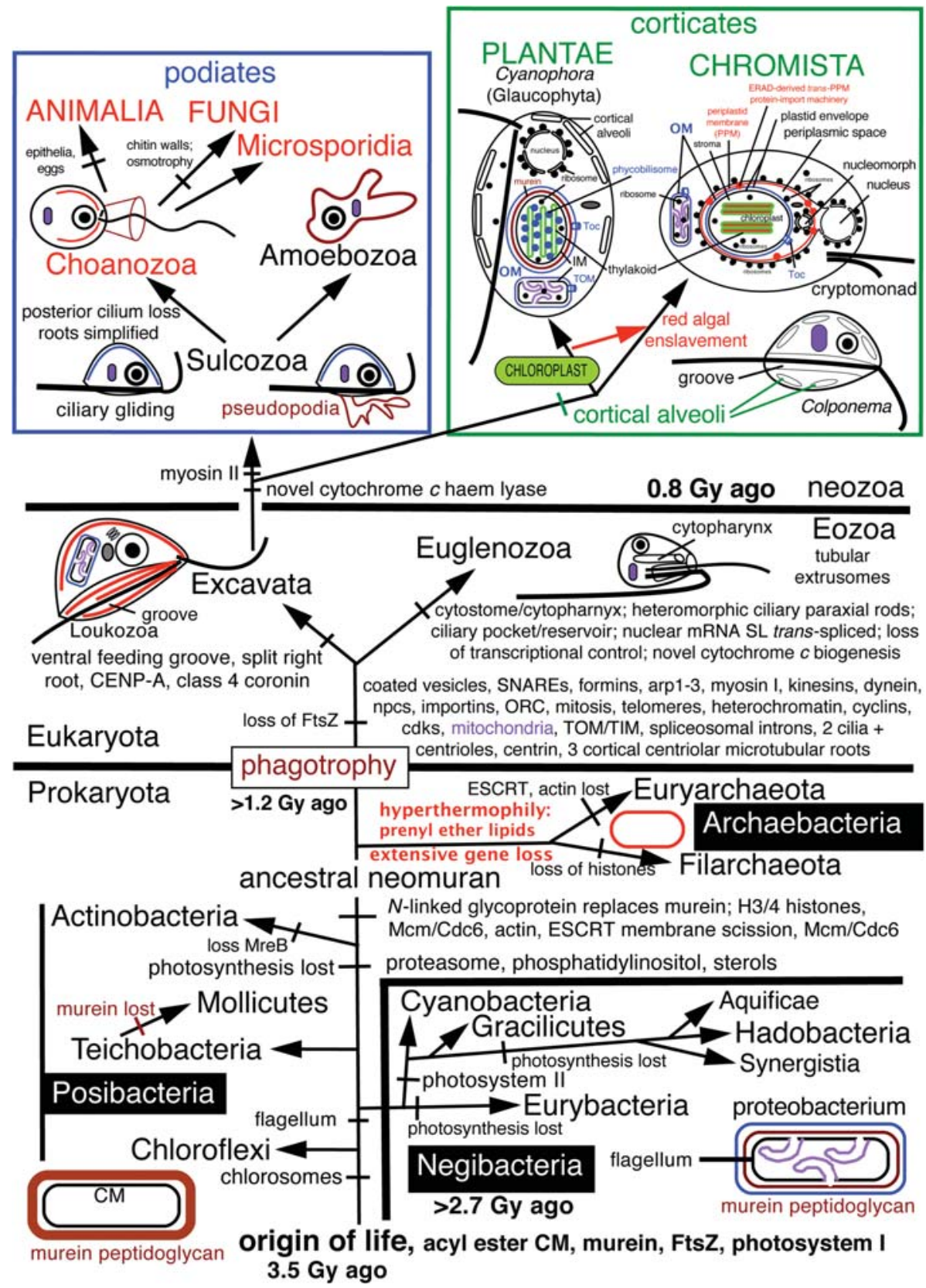

Figure 3. Expanded tree of life showing major subdivisions of ancestral eubacteria and derived neomura. Key innovations in cell evolution primarily involve membranes and cell skeleton. Unibacteria with single membranes evolved three different CM chemistries: Endobacteria (thick-walled Teichobacteria plus derived wall-free mycoplasmas and spiroplasmas [i.e., Mollicutes]) and Chloroflexi, the two most ancient posibacterial subphyla, retained ancestral hopanoids as membrane rigidifiers. Actinobacteria evolved sterols and phosphaphatidylinositol. Archaebacteria, the youngest bacterial phylum, sister to eukaryotes, replaced acyl ester phospholipid bilayers by a stabler isoprenyl ether monolayer to become the first hyperthermophiles. Numerous proteins were lost during their origin and early diversification. (Legend continues on following page.) 
by gene duplications from homologous condensin rings that universally mediate higher-order DNA folding (bacterial nucleoid-folding; eukaryote chromatin-folding). Anaphase chromosome separation is initiated later than centriolar disengagement by ubiquitin-controlled proteasome-mediated proteolysis of separase inhibitors and hundreds of other proteins, all marked by anaphase-promoting complex (APC) ubiquitin ligase (Oliveira et al. 2010) and timed by changes in cyclin phosphorylation (a uniquely eukaryotic cell-cycle control principle) (Nasmyth 1995).

These universally shared cohesin-based features of higher-order DNA folding and segregation strongly argue against past wild speculation that neomura evolved DNA replication independently of eubacteria, quite apart from the

Figure 3. (Continued) The neomuran common ancestor probably arose from a stem actinobacterium by replacing covalently cross-linked cell-wall peptidoglycan by more flexible glycoproteins via an antibiotic-resistant but traumatically wall-less, DNA-segregationally defective intermediate that recovered through revolutionary change in ribosomes/SRPs and evolving histone-stabilized chromatin, causing radical changes to DNAhandling enzymes: the neomuran revolution. Eukaryotes arose by exploiting the new flexible glycoprotein surface to trap and phagocytose bacteria; phagotrophy internalized their digestive system (endomembranes) and genetic system, stabilized by additional histones, novel endomembrane attachments, and nuclear-pore complexes and a novel 3D internal cytoskeleton and novel motors, used for mitosis/cell division and vesicle and ciliary motility, and internalized an $\alpha$-proteobacterium for enslavement as a mitochondrion (synergistically improving food-energy conversion). Eukaryotes diverged early into Euglenozoa (which retained ancestral ciliary gliding on surfaces and divergent DNA replication initiation and mitochondrial protein import machinery, but evolved specialized feeding apparatus for a surface-associated lifestyle) and Excavata, which lost gliding and evolved planktonic feeding by a posterior ciliary groove. Excavata comprise nonamoeboid Loukozoa, often with posterior cilium vanes, plus vane-free Percolozoa ancestrally with alternating amoeboid and flagellate stages (sometimes differentially lost). From a vaned Malawimonas-like loukozoan that simplified cytochrome c biogenesis by evolving unimolecular heme lyase stemmed two derived supergroups of contrasting morphology and lifestyle: (1) Corticates specializing on photic zone planktonic living by evolving cortical alveoli and enslaving cyanobacteria to form chloroplasts (first Plantae [almost all lost phagotrophy] then a secondary enslavement of a red alga to generate photophagotrophic Chromista) (Cavalier-Smith 2013b); many corticates evolved a fourth microtubular ciliary root (R4) absent from podiate and eozoan supergroups. (2) Exclusively heterotrophic podiates, by origin of ventral pseudopodia, and dorsal pellicle associated with reevolved posterior ciliary gliding, with subsequent loss of posterior cilium and its roots to create opisthokonts (names in red) with radically simplified cytoskeleton. Vanes were lost by all neozoa but Colponema, which retained the loukozoan feeding method. Ancestrally, chromists had four kinds of ribosome, four genomes, and novel membrane topology with nuclear-coded proteins imported across the periplastid membrane by novel mechanisms derived by duplications from the ERAD machinery that evolved to export unfolded proteins for proteasome digestion in the first eukaryote (Fig. 2C,D,F); many evolved tubular ciliary hairs that modified feeding in heterokonts (Cavalier-Smith and Scoble 2013). All except cryptomonads lost the nucleomorph and periplastid ribosomes. Long-tailed myosin II that forms antiparallel aggregates mediating contraction of podiate pseudopodia and cytokinetic contractile actomyosin rings probably evolved near the ancestral podiate, assuming that the percolozoan Naegleria got myosin II by LGT from podiates. Very different reticulose/filose pseudopodia evolved in the chromist infrakingdom Rhizaria. Amoebozoa and opisthokonts, formerly grouped as "unikonts," evolved from biciliate Sulcozoa by independently losing gliding (eukaryote cytoskeletal diversification and its coevolution with changing feeding modes are detailed elsewhere: Cavalier-Smith and Chao 2012; Cavalier-Smith and Karpov 2012; Cavalier-Smith 2013a). Ancestrally, photosynthetic Negibacteria retained hopanoids and diversified into eight phyla differing in IM photosynthetic machinery, OM chemistry, and flagellar organization. Eurybacteria comprise Negativicutes (Marchandin et al. 2010) (formerly Selenobacteria: Cavalier-Smith 1992, 2002b, 2006c), Fusobacteria, and Thermotogales. Filarchaeota comprise crenarchaeotes, thaumarchaeotes, and korarchaeotes. Although the origin of the first (stem posibacterial) cell was probably as early as 3.5 Gy ago, the major eubacterial radiation producing their modern (crown) phyla likely occurred subsequently, possibly 2.7-2.5 Gy ago; its essential simultaneity accounts for almost nonexistent resolution at the base of the eubacterial tree (Pace 2009), which coupled with a quantum-evolution-stretched neomuran stem in many sequence trees makes it very hard to place neomura anywhere robustly within the eubacterial tree. 
fact that the genetic complexity of any eubacterial/neomuran intermediate with probably at least a thousand genes could not have been supported by a purely RNA-based genome without the conservatism and evolutionary stasis allowed by efficient DNA repair. The key importance of cell-cycle continuity during eukaryogenesis has too often been ignored; many imaginary intermediates could not have reproduced.

The complex origin of phagotrophy was possibly simplified before full phagocytosis by an intermediate stage importing extracellular prey proteins through Derlin surface-membrane pores, coupled with digestion internally by surface-attached proteasomes before lysosomes evolved (Fig. 2C) (Cavalier-Smith 2009). Proteasomes, originating before actinobacteria and neomura diverged (Cavalier-Smith 2006c), were radically complicated by numerous gene duplications in the eukaryote cenancestor when first participating in novel eukaryotic cell-cycle controls.

\section{L-FORMS AND THE NEOMURAN REVOLUTION AND EUKARYOGENESIS: CELL CYCLE/STRUCTURE COEVOLUTION}

The neomuran revolution was initiated by accidental loss of the posibacterial murein wall. Posibacteria can spontaneously lose murein to become naked L-forms; similar protoplasts can be generated in the laboratory by penicillin, preventing enzymes from resealing murein during growth (Dominguez-Cuevas et al. 2012). Such naked cells survive without bursting in osmotically protected environments and undergo multiform drastic changes, far more extensive than the effects of most DNA mutations: experimentally tractable analogs for the initiating phase of the neomuran revolution.

During eubacterial cell cycles, coordinated DNA segregation, cell growth, and division depend on CM attachment of sister chromosomes, cell wall rigidity, and its geometrically controlled growth and division (Fig. 2A) (Egan and Vollmer 2013). The fission site for divisomes is marked by a GTPase FtsZ filament ring (Adams and Errington 2009; Buske and Levin 2013);
ParA ATPase filaments move replicon origins via ParB-binding condensin-rich centromerelike parS DNA segments (Gruber and Errington 2009; Sullivan et al. 2009); after replication terminates with eubacteria-specific dimer resolution by Xer-recombinase, surface-associated DNA translocases separate termini (Kaimer et al. 2009; Sherratt et al. 2010; Grainge et al. 2011). Murein loss grossly disrupts that elaborate cell-cycle mechanism and osmotically destabilizes cells. L-forms therefore bleb membranes, yielding DNA-less gobbets and polyploid cells with several chromosomes. These traumatized physically and genetically unstable cells over weeks or months can spontaneously become stable L-forms without murein, which can multiply for years and have even been isolated from nature; that indicates extremely strong selection for cell-cycle stabilization in accidental L-forms. Eubacterial chromosome organization (a single replicon with one origin and terminus only) is fundamentally coadapted to progressive DNA segregation throughout the cell cycle and active movement of origins separately from termini (Cavalier-Smith 1987a); that originally unfashionable idea of active movement and orderly cell-surface association of eubacterial DNA is vindicated (Stouf et al. 2013).

Simultaneously, I argued that unique features of eukaryote genetics and cell cycles were caused by rescuing segregationally defective L-forms by evolving mitosis with one-step sudden anaphase segregation of all DNA, necessitated by phagotrophy-induced internalization of membrane DNA-attachment sites (Cavalier-Smith 1987c). Indirectly, novel cell structure changed genetics by shifting selective forces. As adumbrated for eukaryotes alone (CavalierSmith 1975), nucleosomes with histones H3/4 evolved immediately following murein wall loss to stabilize neomuran chromosomes. Histones $\mathrm{H} 2 \mathrm{a}$, b and $\mathrm{H} 1$ evolved in eukaryotes only for mitotic chromosome condensation cycles: prophase compaction to avoid shearing in sudden anaphase, plus telophase loosening for interphase transcription (Cavalier-Smith 2010c). In its neomuran form, the unified phagotrophy and coevolutionary theory of eukaryogenesis coherently explained 48 eukaryotic innovations (Cavalier- 
Smith 1987c), and subsequently still more (Cavalier-Smith 2002c, 2010c).

\section{THE NEOMURAN REVOLUTION, EUKARYOGENESIS, AND ARCHAEBACTERIAL DIVERGENCE}

Mechanistically, the neomuran theory comprises three distinct, interlinked theories, explaining (1) the origin of eukaryotes; (2) the origin of archaebacteria; and (3) that both origins were caused by a single dramatic initiating event, the "neomuran revolution": a radical change in eubacterial cell structure generating a transient, unstable L-form-like, evolutionary intermediate-the neomuran cenancestor (CavalierSmith 1987c). The core ideas of the neomuran theory are as follows: (1) Murein loss and cellcycle destabilization happened immediately before Eukaryote/Archaebacterial divergence.

(2) Stabilization was rapid (over a few years, not thousands or millions) but extended long enough for some changes to occur in common before the phylogenetic split (Table 1) and some (in radically divergent directions) subsequently, separately in eukaryote and archaebacterial sister lineages (Fig. 1). The neomuran revolution was a rescue from trauma that changed cells more radically than standard evolutionary divergence by single-gene mutations or getting preexisting genes from foreign bacteria by LGT. (3) Evolution of phagotrophy simultaneously explains the novel cell structure and genetic system of eukaryotes, both mechanistically and selectively. Transient instability and polyploidy before mitosis was perfected made innumerable simultaneous gene duplications (allowing major genetic innovations) and gene losses. (4) The evolutionary success and cellular divergence of eukaryotes and archaebacteria were because the stabilized neomuran's immediate descendants adopted two entirely novel, contrasting life styles, freeing them from competition with their long-established eubacterial ancestors: phagotrophy and hyperthermophily.

The naked protoeukaryotic lineage invented phagotrophy by phagocytosis and internal digestion of other cells, thereby becoming more efficient predators than any eubacteria, and sexual cell fusion, thereby creating more sharply defined "biological species" with radically different population structure from typically clonal prokaryotes (Cavalier-Smith 1991a). Archaebacteria invented hyperthermophily via novel heat-stable lipids: isoprenoid ethers with two glycerophospholipids covalently linked by their hydrophobic tails, making double-headed tetraether lipids forming a stable membrane monolayer. Life originated as eubacteria under easy mesophilic conditions, although Thermotogales and Aquificales became secondary hyperthermophiles by thermostable-protein LGT from archaebacteria. Fatty acid and isoprenoid synthesis evolved in the cenancestral cell (Lombard and Moreira 2011; Lombard et al. 2012a,b; like many others, they incorrectly root the tree between neomura and eubacteria). Younger archaebacteria were ancestrally hyperthermophiles, although some subsequently became mesophilic by LGT from eubacteria, reverting to lipid bilayers, unavoidably retaining isoprenoid diethers because their hyperthermophilic cenancestor irretrievably lost ancestral acyl ester biosynthetic machinery. Because evolving archaebacterial heat-stable lipids was enzymatically simple, they became the world's first hyperthermophiles by gradually modifying numerous proteins enabling spread into ever-hotter habitats free of competitors. The neomuran mevalonate pathway for isoprenoid synthesis was

Table 1. Key stabilizing innovations during the neomuran revolution

1. MreB becomes actin; stabilizes against osmotic stress

2. ESCRT-III filaments for membrane division during cytokinesis

3. DNA gyrase (ATP-using active supercoiler) lost; replaced by histones H3/4 (later lost by crenarchaeotes); passive wrapping of DNA around nucleosomes protects; Mcm proteins

4. SRP adds cotranslation arrest domain

5. $\mathrm{N}$-linked glycoproteins 
already present in their posibacterial ancestor (archaebacteria replaced some enzymes) as was a relative of the enzyme making $s n$-glycerol-1phosphate to which archaebacteria alone attach isoprenoid tails (Peretó et al. 2004). Probably mevalonate and methylerythritol phosphate (MEP) isoprenoid synthesis pathways both originated in early posibacteria and were differentially lost (notably MEP during the neomuran revolution and mevalonate by many eubacteria); LGT was rarer than earlier claimed (Lombard and Moreira 2011).

Membrane stability also involved retaining contiguous laterally interacting semicrystalline surface glycoproteins as an S layer, like the nonglycosylated S layer outside the thick murein walls of their posibacterial ancestors. Wall rigidity enabled some archaebacteria to retain the ancestral eubacterial FtsZ cell division machinery but prevented phagotrophy or sexual cell fusion evolving. Therefore archaebacterial cell structure, growth, division, and genetics remained fundamentally bacterial or prokaryotic. Early claims that archaebacteria are a "third form of life" in addition to eukaryotes and prokaryotes/ bacteria are thus falsified, despite misleading, confusing, purely propagandistic name changes that some of us never accepted (deleting "bacteria" from archaebacteria and "eu" from eubacteria); as Archaea Koch and Baerendt, 1854 is a genus of Madagascan spiders first discovered in Baltic amber (Dippenaar-Schoeman and Jocqué 1997), it was doubly confusing to use the same name for a group of bacteria and to make it ambiguous whether "bacteria" refers to all prokaryotes, as it properly does (CavalierSmith 2007a), or just eubacteria (Woese et al. 1990). In fact, archaebacteria are a third form of bacteria (Figs. 1 and 3). Contrary to early misconceptions, still sadly widespread, their discovery was irrelevant to the origin of life, yet crucial for understanding eukaryote origins because their striking molecular differences from eubacteria and marked partial similarities to eukaryotes enabled four strong deductions, universally accepted:

1. In conjunction with strong similarities of mitochondria to $\alpha$-proteobacteria (John and Whatley 1975; Gray 1992), it showed that mi- tochondria could not have evolved from the same ancestor as the rest of the eukaryotic cell. One must accept that eukaryotes are evolutionary chimeras of a moderately changed $\alpha$-proteobacterium (negibacterium) and far more complex, radically different host cell (Cavalier-Smith 2002c).

2. That host was more closely related to archaebacteria than to eubacteria.

3. Differences between it and eubacteria evolved in two stages: those shared with archaebacteria first; organizationally more radical, uniquely eukaryotic inventions subsequently.

4. In conjunction with marked similarities between chloroplasts and cyanobacteria, one must accept that the host component was a heterotroph, chloroplasts being implanted subsequently by phagocytosis and radical transformation of cyanobacteria (CavalierSmith 2000, 2013b).

\section{ACTINOBACTERIA, LIKELY NEOMURAN SISTERS}

The neomuran theory identified exosporeforming actinobacteria (e.g., Mycobacterium, Streptomyces), all possessing phosphatidylinositol (unlike other prokaryotes), crucial for eukaryote cell signaling, and cholesterol, and many with $40 \mathrm{~S}$ proteasomes (unlike other eubacteria), as more likely posibacterial ancestors of neomura than Teichobacteria, the posibacterial class with thick teichoic-acid-containing walls and endospores (e.g., Bacillus), although Valas and Bourne (2011) gave reasons favoring Teichobacteria instead. Their and my arguments are simultaneously satisfied if the ancestor was a phylogenetic intermediate, sister to actinobacteria but derived from a Teichobacteria-like ancestor (Fig. 3); this also reconciles neomuran theory with sequence trees that typically place neomura in an unresolved position close to the base of the eubacterial radiation in which branching orders among the three main posibacterial groups Actinobacteria, Endobacteria, and Chloroflexi and negibacterial phyla are ill-resolved (Pace 2009; Woese 2013), as well as with actinobacteria-specific signatures 
(Gao and Gupta 2005, 2012; Gao et al. 2006, 2009; Servin et al. 2008). Actinobacteria are immediately adjacent to archaebacteria on two of the five protein-family splits networks of Dagan et al. (2010) based on 191 bacterial genomes and separated from them by Endobacteria on a third, so the majority support a neomuran relationship with Posibacteria, with actinobacteria favored as the closest. Cyanobacteria are also adjacent on three, although their negibacterial cell structure makes a direct relationship less likely, whereas Gracilicutes are overall more distant; thus, of the limited bacterial megagroups sampled, posibacteria and cyanobacteria were the best candidates for the closest relatives to neomura. It is a pity that the analyses excluded Eurybacteria and Hadobacteria (data for Chloroflexi were then unavailable). Actinobacteria alone in prokaryotes have a CTP-dependent cardiolipin synthetase needed for mitochondria (Sandoval-Calderón et al. 2009).

\section{COTRANSLATIONAL SECRETION DURING THE NEOMURAN REVOLUTION AND EUKARYOGENESIS}

The neomuran cenancestor evolved shared features of ribosomes (anisomycin inhibition of peptidyl transferase; chloramphenicol resistance; new proteins), ribosomal rRNA processing (fibrillarin; U3 and C/D- and H/AC-box snoRNA guides for pre-rRNA cleavage and base modification), tRNA protein-spliced introns, and signal recognition particle (helix 6; SRP19 protein) that are absent in eubacteria and evolved from the simpler system of Posibacteria (Cavalier-Smith 1987c, 2002b). Neomuran glycoproteins are made by ribosomes docked onto a membrane by the ribonucleoprotein signal recognition particle (SRP) that recognizes their amino-terminal hydrophobic signal sequence and membrane-embedded SRP receptors and transfers the signal hairpin into the membrane. The rest of the unfolded protein then crosses the membrane via an openable protein channel, folding correctly on the other side. Before signal peptidase removes its signal peptide, oligosaccharyltransferase attaches a presynthesized hexose-rich oligosaccharide by its basal $\mathrm{N}$-acetyl- glusosamine to one or more asparagines two amino acids upstream of a serine or threonine. The oligosaccharide is synthesized sequentially on the ribosomal face of the membrane while covalently attached (in eukaryotes always via $\mathrm{N}$-acetylglucosamine; in archaebacteria ancestrally thus) to a phosphorylated polyisoprenol carrier (dolichol phosphate or pyrophosphate). This hydrophilic core oligosaccharide is flipped across the membrane by flippase protein. This complex machinery is strongly conserved and homologous between archaebacteria and eukaryotes, proving the central thesis of the neomuran theory and refuting the progenote idea (Woese and Fox 1977). The common ancestor of neomura, undeniably with all of these mechanisms, was an advanced cell with extremely sophisticated translation, transcription, DNA replication and segregation, and a lipid membrane with numerous embedded proteins. There certainly was an historical changeover between acylester membrane lipids (eukaryotes and eubacteria) and isoprenoid ethers of archaebacteria: one was not converted into the other (chemically impossible). Instead, one replaced the other, hyperthermophily being the strong selective advantage for replacing eubacterial by archaebacterial lipids (Cavalier-Smith 1987b,c), there being none for the reverse; the transient intermediate had both types (Cavalier-Smith 2002b).

Eubacterial murein peptidoglycan is analogous to neomuran $N$-linked glycoproteins: both comprise amino acids, sugars, and amino sugars; synthesis involves transfer of hydrophilic core units containing $\mathrm{N}$-acetylglusosamine across the hydrophobic CM, after being synthesized on its cytosolic face by sequential covalent attachment to a phosphorylated polyprenol. Murein consists of an alternating copolymer of amino sugars $N$-acetylglusosamine and $N$-acetyl muramic acid covalently cross-linked by oligopeptides: its precursors flipped across CM on undecaprenol are muramopeptides with two amino sugars and four amino acids. Common biogenetic involvement of $\mathrm{N}$-acetylglucosamine and isoprenoid carriers suggested an evolutionary relationship (Cavalier-Smith 1987c); I proposed that the ancestral neomuran posibacte- 
ria-derived L-form lost muramic acid, omitted the amino acids, and added extra hexoses, and the same oligosaccharyltransferase added it to preexisting S-layer proteins, yielding the first $N$-linked glycoproteins (Cavalier-Smith 1987c). BLAST analysis now strongly supports that: as predicted, eukaryotic and archaebacterial dolichol-dependent oligosaccharyltransferases making $N$-linked glycoproteins are homologous, strongly conserved, and homologous with, but somewhat less similar to, the undecaprenol-associated oligosaccharyltransferases of teichobacterial and actinobacterial posibacteria that make murein. Therefore, almost certainly, neomuran $\mathrm{N}$-linked glycoproteins did evolve from preexisting posibacterial oligosaccharyltransferases that previously made murein. The similarity of neomuran transferases is much greater to those of posibacteria than to any Negibacteria except a few $\delta$-proteobacteria, for example, the myxobacterium Stigmatella; these few $\delta$-proteobacterial oligosaccharyltransferases perhaps underwent LGT from neomura to myxobacteria.

The eukaryote rough ER cotranslational protein channel comprises Sec61 and ancillary $\alpha, \gamma$-subunits; these evolved from the SecYEG prokaryote translocon when phagotrophy internalized the CM during eukaryogenesis. The plasma membrane also kept prokaryotic $A B C$ transporters for rare posttranslational protein secretion, for example yeast mating hormones, but other protein secretion mechanisms were lost or transformed beyond confident recognition during eukaryogenesis. Loss of type IV secretion (responsible for bacterial conjugation in archaebacteria and eubacteria) largely explains why LGT is much rarer in eukaryotes than bacteria. The TatAC bacterial pathway for exporting folded proteins (using the same signal peptidase as Sec for unfolded ones) (Palmer and Berks 2012) is absent in eukaryotes, but the more complex homologous negibacterial Tat $\mathrm{ABC}$ was retained by chloroplast thylakoids.

Universal Sec arose in the first cell, as did TAT and ABC transporters, and two types of signal peptidases: type I for most proteins and type II specific for lipoproteins. Type III, used for secreting prokaryotic flagellar proteins and pilins and in archaebacteria also for many other proteins, probably evolved subsequently with flagella. Types II and III signal peptidases were lost during eukaryogenesis. Eubacterial SecA that unfolds folded proteins for threading through SecY was lost when the neomuran ancestor made Sec more cotranslational, by the novel neomuran arrest domain of SRP (Cavalier-Smith 2002b). Bacterial TAT secretes folded globular proteins across CM. Cavalier-Smith (2006a, 2009) suggested that eukaryotes modified TAT for protein import into peroxisomes. Import of soluble peroxisomal enzymes uses two alternative topogenic sequences: a nonapeptide recognized by type II receptors and the carboxy-terminal (type I) SKL motif by receptors; although TAT recognizes a carboxy-terminal RR motif, Pex5, the SKL receptors like TAT use tricopeptide repeats (Rucktäschel et al. 2010) and thus might be related.

\section{COEVOLUTION OF MITOCHONDRIAL, ER, AND PEROXISOMAL RESPIRATION AND SEGREGATION}

These three oxygen-consuming respiratory organelles - the mitochondrion, the ER, and the peroxisome-coevolved in early eukaryotes, partitioning aerobic metabolism among them, making aerobic phagotrophy more efficient. Early mitosis was open or semiopen, with peroxisomes segregated to daughter cells by attachment to the nuclear envelope through the cell cycle. Space constraints prevent discussing the origin of mitochondria, probably from a photosynthetic $\alpha$-proteobacterium contemporaneously with the origin of cilia and nucleus (Cavalier-Smith 2006b, 2007b), and how its negibacterial reproduction (originally using FtsZ-associated division) was modified and integrated into the eukaryotic cell cycle, partly divergently in excavates and Euglenozoa (Kinetoplastea segregate mitochondria by centriole attachment) (Gluenz et al. 2011); they and diplonemids evolved glycosomes from peroxisomes (Cavalier-Smith 1997; Gualdrón-López et al. 2012). Peroxisomes originated marginally before mitochondria, not long before, as De Duve once thought. Although they probably evolved by pri- 
The Neomuran Revolution and Origin of Eukaryotes

mordial divergence from the ER (Cavalier-Smith 1975; Gabaldon 2010), not by symbiogenesis of bacteria as De Duve proposed, they evolved novel division machinery, multiplying mainly by growth and division (Pieuchot and Jedd 2012), thus becoming effectively distinct genetic membranes (Cavalier-Smith 2004). Mitochondria, and subsequently plastids, apparently coopted this division machinery (Pan and $\mathrm{Hu} 2011$ ), just as mitochondria arguably duplicated the peroxisomal ADP/ATP exchanger when evolving IM carriers, the key to their enslavement (Cavalier-Smith 2006b), subsequently donating duplicates to chloroplasts (Cavalier-Smith 2000). Ancestrally, peroxisomes were probably segregated through specific nuclear-envelope attachments, retained by diverse protists (Cavalier-Smith and Oates 2012).

Separating ATP-generating and degradative respiratory cytochromes in mitochondria and ER following the differentiation of peroxisomes and endomembranes (Fig. 2) made aerobic exploitation of prey more efficient, but, contrary to Lane and Martin (2010), mitochondria did not cause large eukaryote genomes. Increased genome size resulted from the origin of the novel phagotrophy-driven cytoskeleton, eukaryotic cell cycle, and nuclear architecture with nuclear pores, which collectively transformed the machinery and selective forces acting on chromosomes, and by allowing marked (initially phagotrophy-driven) increases in cell size imposed upward coevolutionary pressures on genome size, which controls nuclear volume, which invariably coevolves with cell size (Cavalier-Smith 2005, 2010c). Symbiogenesis did not drive these innovations; for its importance to eukaryote cell evolution, see Cavalier-Smith (2013b).

\section{DIVERSE CELL BIOLOGY OF FILARCHAEOTA CLARIFIES NEOMURAN EARLY EVOLUTION}

Archaebacterial multigene trees show Korarchaeota and Thaumarchaeota forming a clade with Crenarchaeota (Podar et al. 2013), all here grouped as subphylum Filarchaeota (Table 2) to emphasize that they ancestrally had two eukaryote-like filamentous cytoskeletal proteins: actin (Yutin et al. 2009) and ESCRT-III filaments for cytokinesis (Hobel et al. 2008; Samson et al. 2008; Ettema and Bernander 2009; Makarova et al. 2010). A direct eukaryotic origin from filarchaeotes is implausible because they lack the right lipids and scores of proteins (e.g., dynamin, Hsp90) vital for making eukaryotes. The archaebacterial cenancestor was not a crude gene-poor progenote but had $>1000$ genes, undergoing extensive genomic reduction after diverging from eukaryotes (Cavalier-Smith 2002b, 2007b): differential losses during archaebacterial radiation reduced genes from ancestrally 2000 (Csürös and Miklós 2009; Wolf et al. 2012), yielding lineages lacking different subsets of proteins necessary for making eukaryotes, all originally present in the more complex ancestral neomuran. The mechanistically implausible idea of host archaebacterial lipid replacement by mitochondria (Martin and Müller 1998) can "explain" hypothetical loss of isoprenoid ether lipids but not acquisition of phosphatidylinositol, cardiolipin (actinobacteria alone in prokaryotes have CTP-dependent cardiolipin synthetase), and sterols, all readily supplied by the neomuran ancestor. It is far simpler that this ancestor stabilized its genome by evolving chromatin, its cytoplasm by actin, and division by ESCRT before eukaryotes and archaebacteria diverged, filarchaeotes losing dynamin, and euryarchaeotes losing actin and ESCRT. Many trees suggest archaebacterial holophyly (Yutin et al. 2008), but despite incontrovertible evidence for multiple losses within Filarchaeota, some investigators ignore the possibility of eurybacterial actin/ESCRT loss and suppose that eukaryotes evolved from filarchaeotes. Contradictorily, others assumed that eukaryotes evolved from euryarchaeotes (where eukaryotic-like glycosyltransferase is more widespread than in crenarchaeotes) because of histone similarities (Reeve et al. 2004; Cubonova et al. 2005) or the phylogenetically refuted and mechanistically implausible hypothesis that eukaryotes evolved from a methanogenic euryarchaeote (Martin and Müller 1998).

Given huge problems in cell biology that massive replacement of host lipids and proteins entails in a hypothetical archaebacterial origin, one must not uncritically accept certain mul- 
T. Cavalier-Smith

Table 2. Classification of new archaebacterial subphylum Filarchaeota ${ }^{a}$

\title{
Class 1 'Korarchaeota'
}

Name suggested by Barns et al. (1996) at the grossly inflated 'kingdom' rank; should be a class, which cannot be made formally until 'Candidatus Korarcheum' or another contained genus is legitimately published.

\section{Class 2. 'Thaumarchaeota'}

Name suggested by Brochier-Armanet et al. (2008) at the unwisely inflated rank of 'phylum'; should be a class, but not formally possible until a genus within it is legitimately published.

Order 1. 'Cenarchaeales' Cavalier-Smith, 2002 was illegitimate as the widely used 'type genus' 'Cenarchaeum' is still not formally published and thus illegitimate.

Order 2. 'Caldiarchaeales' may be a suitable name for the clade containing 'Candidatus Caldiarchaeum', which does not deserve the phylum rank suggested by Nunoura et al. (2011) as 'Aigarchaeota'.

Class 3. Crenarchaeota Cavalier-Smith, 2002 (later synonym: Thermoprotei [Reysenbach 2002])

Their stronger hyperthermophily than other archaebacteria probably caused more extensive loss of ancestral proteins (e.g., histones).

\begin{abstract}
${ }^{a}$ Diagnosis: Archaebacteria containing actin and/or ESCRT-III filaments, unlike Euryarchaeota. Type order Thermoproteales Zillig and Stetter, 1982. Etymology: Filum L. thread, to show they have one or both of these cytoskeletal filaments: archae Gk ancient. Comment: Equivalent to the too highly ranked informal 'TACK superphylum' (Guy and Ettema 2011), who demonstrate numerous independent losses of neomuran proteins within Filarchaeota and Euryarchaeota, postulating loss of actin and ESCRT-III by Euryarchaeota, which retained FtsZ and histones, unlike most Filarchaeota, is much more parsimonious than accepting that eukaryotes are sisters to Filarchaeota, as some trees suggest (Williams et al. 2012). I give a formal definition despite no taxa above classes currently having standing in prokaryotic nomenclature; the code needs changing to encompass phylum and kingdom names (as for classes, do not apply priority to them). Clades DSAG/AAG/ MHVG of Guy and Ettema (2011) should not be a separate phylum, but may belong in Thaumarchaeota when better characterized. Filarchaeota contains all archaebacteria except subphylum Euryarchaeota (with five classes: Cavalier-Smith 2002b), in which I now place 'Nanoarchaeum', which will not deserve separation from other archaebacteria at higher rank than an order after being formally named, contrary to those who treat it as a 'phylum'; its deep divergence from other euryarchaeotes looks like a typical artifact of rapid evolution after parasitic reduction, as in mycoplasmas, microsporidia, and Mikrocytos.
\end{abstract}

tigene trees emphasizing ribosomal proteins showing eukaryotes as sisters to Filarchaeota only, not to all archaebacteria (Williams et al. 2012), as refuting the neomuran theory. As Valas and Bourne (2011) explain, most of those 31 proteins (Williams et al. 2012) underwent rapid (possibly tree-biasing) quantum-evolutionary changes in ribosomes during the origins of eukaryotes and archaebacteria, as earlier argued for rRNA (Cavalier-Smith 2002b); the very long stem at the base of eukaryotes in these trees is precisely the condition most likely to ensure that a genuine outgroup (sister) is misplaced within the ingroup (here archaebacteria), as decisively shown by Shavit et al. (2007). I therefore consider this probable artifact the simplest way to reconcile contradictory trees showing archaebacterial holophyly (probably right for reasons previously detailed) (Cavalier-Smith 2010c) and paraphyly (probably this longstem artifact)—see also Gribaldo et al. (2010), who do not yet take seriously the possibility that neomura arose from eubacteria, despite it simply resolving the impasse that they discuss (although unlike most overinfluenced by the progenote myth that ignored cell biology and palaeontology, they are open-minded enough to mention it as a potential solution to which they may eventually be driven!). Even the Williams et al. tree suggests that eukaryotes and archaebacteria arose nearly contemporaneously, reconcilable with fossil dates and eukaryote multigene trees only by accepting that archaebacteria are at least twice as young as eubacteria and evolved from them (Cavalier-Smith 2006a, 2013a). Neomuran theory holds that eukaryotes and archaebacteria diverged almost immediately after neomura originated, and euryarchaeotes and filarchaeotes diverged immediately thereafter. It therefore predicts that it should be extremely hard for multigene trees to decide whether eukaryotes are sisters to or nested deeply within archaebacteria, expecting some trees to show one and some the other, exactly 
as is observed. Above all, these trees provide no evidence that archaebacteria are as old as eubacteria. If they were, they would be two to three times older than eukaryotes, which should make multigene trees nest eukaryotes shallowly within archaebacteria, which they do not.

\section{SUCCESSIVE GLIDING, FISHING, AND SWIMMING STEPS IN THE PHAGOTROPHY- RELATED ORIGIN OF CILIA}

Ciliary biogenesis and locomotory undulation are extremely complex, requiring more than 660 genes (Carvalho-Santos et al. 2010, 2011), and evolved autogenously by modifying the microtubular cytoskeleton and associated motors. Early theories inadequately explained how that complexity evolved (Cavalier-Smith 1978a, 1982). Centrioles are so intricately constructed (Li et al. 2012) that their ontogeny probably closely recapitulates phylogeny: amorphous germinative discs containing $\gamma$-tubulin initiate assembly of ninefold cartwheels, then singlets, then doublets/triplets (Cavalier-Smith 1974; Jerka-Dziadosz et al. 2010; Gogendeau et al. 2011). Intraflagellar transport (IFT) machinery for intraciliary protein movement evolved from COPI-coated vesicles (Jékely and Arendt 2006; van Dam et al. 2013), probably contemporaneously with nuclear pore complexes from COPII vesicle coats (Cavalier-Smith 2010c); ciliary gliding, using the same machinery, probably arose before swimming (Cavalier-Smith 2009). In remarkable harmony with the simultaneous coevolutionary origin of cilia and nuclei thesis (Cavalier-Smith 1987c), cilia are a distinct cell compartment into which ciliary proteins are targeted across a basal "ciliary pore complex" by machinery containing importin and nucleoporins used for nuclear import, similarly governed by a RanGTP/GDP gradient, and recognizing ciliary localization signals (CLS) related to nuclear localization signals (NLS) (Fan et al. 2011; Kee et al. 2012). Nuclear import machinery was either partially coopted and modified for cilia or nuclear and ciliary import diverged simultaneously from vesicle coats.

Like bird feathers, which originated to insulate small running dinosaurs (easier), subse- quently modified for flight (harder), Figure 4 outlines an autogenous origin of centrioles and cilia with two functional shifts and three successive selective forces: (1) kinesin-driven ciliary gliding and compartmentation for surface motility; (2) protociliary duplication and transformation making a differentiated prey trapping anterior ciliary fishing rod (as Phalansterium cilium does today: Smirnov et al. 2011) and a posterior gliding cilium for enhancing phagotrophy; and (3) ciliary bending, initially to improve fishing and subsequently allow swimming. Thus, improved phagotrophy probably preceded swimming as a selective advantage, and final stages in centriole and ciliary evolution followed ciliary duplication, unlike previous theories. The resulting cenancestral eukaryote immediately diverged into (a) swimming excavates by losing gliding, evolving a ventral groove with a split right centriolar root and a posterior ciliary undulation drawing in food; and (b) posteriorly gliding Euglenozoa by evolving a ventral root-supported cytostome for surface feeding, consistently with rooting the tree between excavates and Euglenozoa (Figs. 1 and 3 ), with contrasting centriole-anchoring cytoskeletons (Cavalier-Smith 2013a). Because gliding and ciliary surface feeding are mechanistically simpler, and gliding could be initiated by preexisting cytoskeletal properties (Fig. 4A), their historically preceding ciliary beating allowed the seemingly irreducible complexity of ciliary beating to evolve in simple stages; each had clear selective advantages, improvable gradually by blind mutations, needing no symbiogenesis (Margulis 1970), no viral input (Satir et al. 2008), and no intelligent design.

Centriolar duplication and mitosis coevolved with new cell-cycle controls (Fig. 5). Although archaebacteria share eukaryote-like DNA replication machinery, cycle controls remained prokaryotic because they retain cellsurface-attached DNA, ParA P-loop ATPase filaments, and typically ParB centromere-like proteins for moving chromosomes (Bernander et al. 2010), although the ancestral parS DNA sites that they bind are rarely recognizable (Livny et al. 2007), probably through histonestimulated divergence. Eukaryotic cycle control 

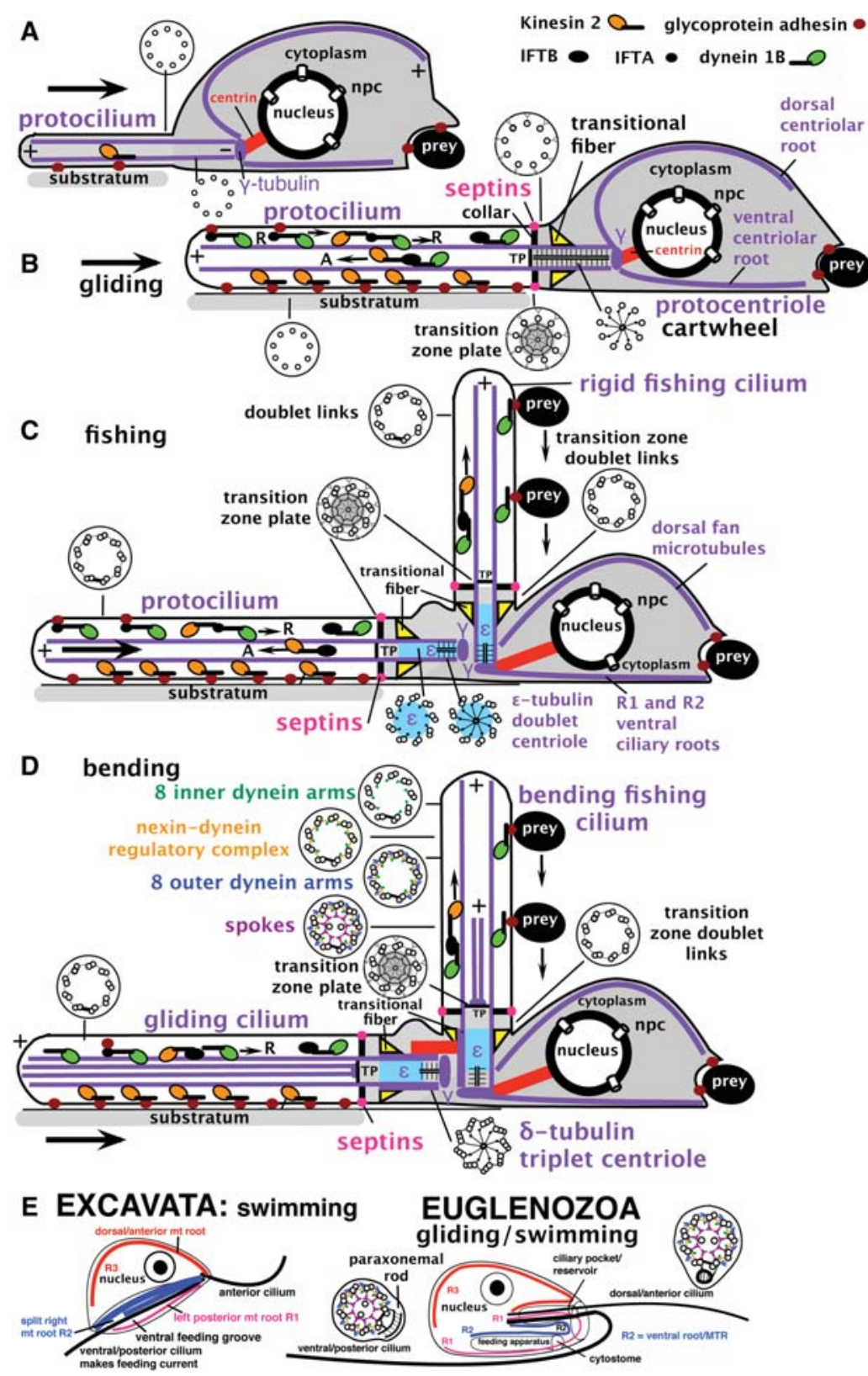

Figure 4. Autogenous origin of cilia with successive origins of different ciliary components under three contrasting selective forces. (A) During or just after the origin of nuclear pore complexes (npc Fig. 2), singlet microtubules from the $\gamma$-tubulin protocentrosome push out the plasma membrane as a protocilium by which plus-end-directed kinesin-2 motors (Verhey et al. 2011) attached by their tails to glycoprotein surface adhesins sticking to the substratum propel its microtubules forward (arrow) in primitive gliding motility, enabling cells to find fresh prey on the substratum as phagotrophy locally depletes it. (B) Posterior ciliary gliding was improved by attaching microtubules firmly to the cell surface by protocentriolar transitional fibers (proximally) and Yshaped membrane connectors (slightly distally) plus ciliary compartmentation dependent on novel diffusion barriers (septin filaments in ciliary membrane base: Carvalho-Santos et al. 2011), central distal transition plate (TP), and a peripheral dense collar at the distal end of the Y-connector region, associated with npc proteins with novel ciliary import machinery using npcs and importin- $\beta 2$ and NLS-related CLS targeting sequences (located in TP and/or collar). (Legend continues on following page.) 
(including cyclins, origin of ubiquitin from ancestral neomuran ubiquitin-like proteins [Pearce et al. 2008; Maupin-Furlow 2013], and proteasome complexification), were therefore consequences not of novel neomuran chromatin and DNA-replication machinery but of radical eukaryote-specific cell structural innovations, especially phagotrophy-driven DNA internalization to endomembranes and origins of TubZ-GTPase-related microtubules, $\gamma$ tubulin centrosomes, centrioles/cilia, and mitosis.

Figure 4. (Continued) Dynein 1b, the first dynein, evolved (by gene-duplicating its common ancestor with the related $\mathrm{AAA}^{+}$ATPase midasin/REA1 that mechanically strips biogenesis factors from $60 \mathrm{~S}$ preribosomal subunits just before they exit the nucleus: Garbarino and Gibbons 2002; Kressler et al. 2012) to recycle distal adhesins left at the protociliary tip by axoneme gliding. Anterograde movement of dynein improved by carriage on kinesin-2driven IFTB particles that evolved from CopI coat proteins, and special SNAREs evolved for basal delivery of ciliary membrane precursor vesicles with distinctive proteins and lipids. Protocentrioles were rigidified by a hubspoke core, microtubules fixed at nine by ninefold SAS-6 hub assembly (Guichard et al. 2012). Cross-links rigidified the axoneme, the two on its substratum face having numerous extra-rigid linkers linking them like sled runners (subsequently becoming doublets 1 and 2 of Chlamydomonas: Lin et al. 2012). Novel proteins (e.g., Rib43a: Norrander et al. 2000) stabilized A-tubules and the bases of centriolar root microtubules (dorsal and ventral fans) compared with transient spindle microtubules. $(C)$ Ciliary duplication produced a younger "fishing" cilium projecting into the medium for trapping swimming bacteria, pulling them baseward by minusdirected dynein $1 \mathrm{~b}$, for phagocytosis. Centrin plus novel proteins orthogonally rigidly connected the two protocentrioles now with doublets (architecture [Nicastro et al. 2011] perhaps determined by novel microtubule inner proteins, for example PACRG (Ikeda et al. 2007; Ikeda 2008), stabilized by a scaffold containing $\varepsilon$-tubulin [blue]). PACRG-interacting Rib72 (Ikeda et al. 2003) differentiated ciliary from centriolar doublets. Centriolar transformation temporally and physiologically differentiated the two cilia and made separate left and right ventral microtubular roots. $(D)$ Successive dynein duplications generated inner arms (top: sufficient for bending [Heiss et al. 2013] as doublet 1-2 linker excluded arms from doublet 1, destroying ninefold symmetry; then the nexin-dynein regulatory complex [Heuser et al. 2009, 2012; Lin et al. 2011; Bower et al. 2013] for calcium regulation of beat; then outer dynein arms for greater power, and the center pair [nucleated by $\gamma$-tubulin on TP, and fixed so did not rotate] with new arms [Carbajal-Gonzalez et al. 2013] and kinesin-9 [Wickstead et al. 2010] and spokes [Barber et al. 2012] to modulate beat mechanics [not inherently needed for planar beat: Idei et al. 2013]) to draw in more prey by water currents. For pictorial simplicity, the cell body is proportionally too small and ahead of the cilia, but probably at stage $\mathrm{b} / \mathrm{c}$ the cytoskeleton geometrically rearranged to lift the cell body from the substratum and put the ciliated cell apex at the front, which is mechanically stabler (found in all extant posterior ciliary gliding eukaryotes), entailing a basal stable bend ([E] mechanism unknown) for the posterior gliding cilium. Many complexities of present cilia (Mizuno et al. 2012) probably evolved subsequently to improve efficiency but would not have been essential for their origin, for example, association of IFTA/B into one complex and of these into distinct anterograde and retrograde trains (Pigino et al. 2009; Buisson et al. 2013), and addition of BBsomes, likely adaptors for improving retrograde transport of some proteins (Lechtreck et al. 2013) and sensory functions (sensation [Jékely and Arendt 2006] is less plausible than gliding for the original function), and beat pattern modulators. (E) The cenancestral eukaryote diverged to form swimming excavates that abandoned gliding and undulate the posterior cilium to draw prey into the ventral groove supported by a split right ventral centriolar root R2 (blue), and Euglenozoa that ancestrally retained gliding, added a cytopharnyx supported by ancestrally unsplit R2 and dissimilar paraxonemal rods (probably attached to the specially linked doublet 1-2 homologs) to broaden and further rigidify the posterior cilium for stabler gliding, and parallelized their centrioles within a ciliary pocket. After losing phagotrophy, saprophytic, parasitic, and photosynthetic Euglenozoa lost gliding and developed swimming by the anterior (Euglenophyceae) or posterior (trypanosomatids) cilium; some bacterivores ( petalomonads) lost the posterior cilium, presumably recruiting dynein $1 \mathrm{~b}$ for anterior ciliary gliding. All other eukaryotes evolved from excavates (Fig. 3); Apusozoa, Cercozoa, and the heterokont Caecitellus reevolved posterior ciliary gliding, presumably using kinesin-2. The V-fiber, with associated acorn-base attached distally to centriole 1-2 triplets (at least in neokaryotes: Geimer and Melkonian 2005), demarcates the centriole from the transition zone and perhaps evolved in the cenancestral eukaryote; its rotational asymmetry and that of centriolar root attachments to specific triplets probably reflect an asymmetric doublet "numbering machinery" that probably evolved in the earliest gliding protocilium $(B)$. 
T. Cavalier-Smith

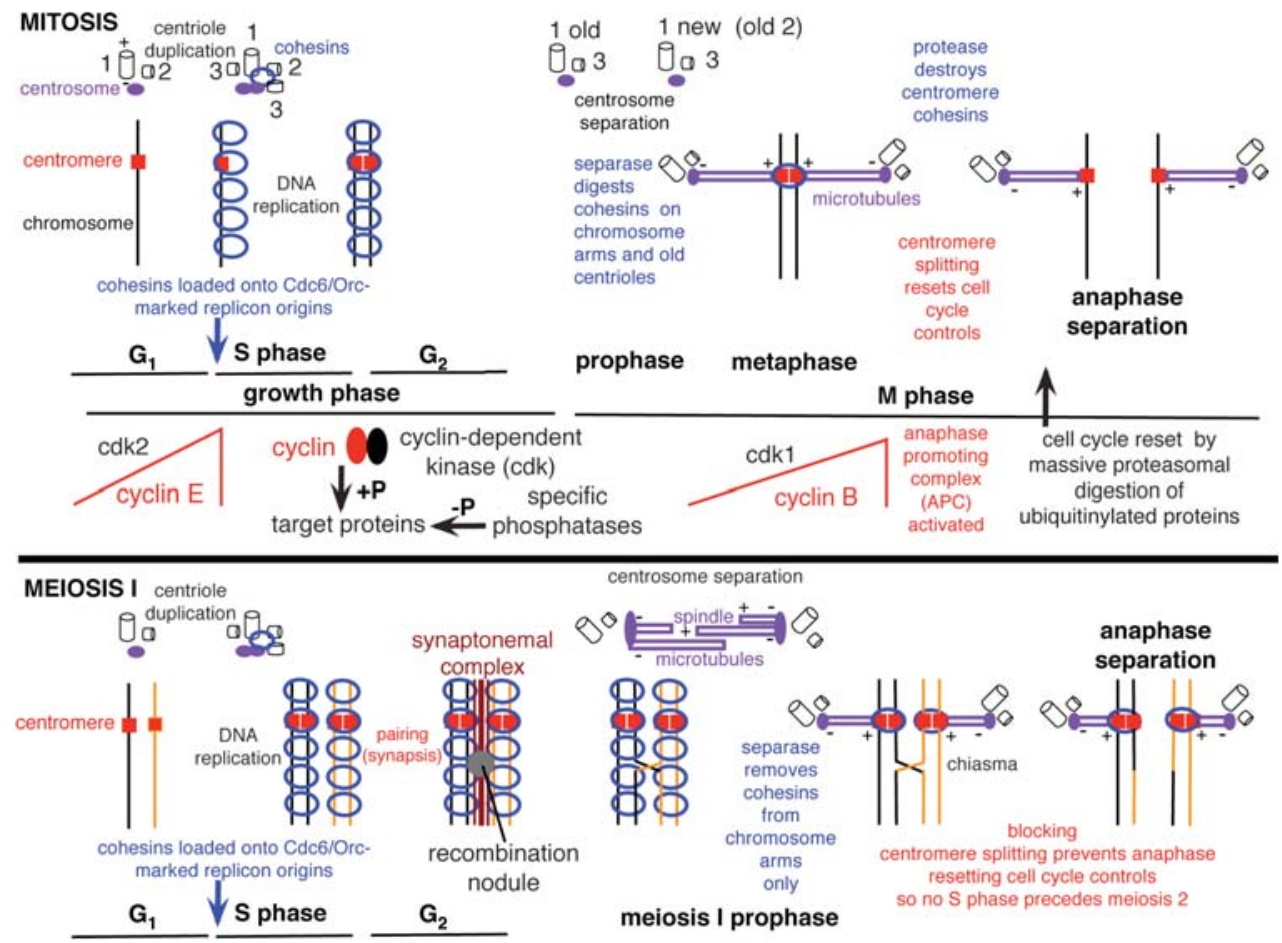

Figure 5. Eukaryote cell-cycle logic and evolution. Complexes of cyclin-dependent kinase (CDK) and cyclins control the eukaryotic cell cycle by phosphorylating numerous proteins, timed by growth-dependent increases in cyclins and their sudden proteolysis (red curves) (Nasmyth 1995). Cyclins share a domain with neomuranspecific transcription factor TFII, and CDKs evolved from posibacterial serine-threonine (S/T) kinases. Originally one cyclin could have controlled S-phase initiation and anaphase onset using a lower threshold for the former switch (Novak et al. 1998; Tyson and Novak 2008; Harashima et al. 2013); gene duplication enabled better control by cyclinE/cdk2 (for DNA replication and centriole duplication) and cyclin B/cdk1 to activate the anaphase promoting complex (APC), the ubiquitin ligase that initiates anaphase resetting of cell-cycle controls via proteasome degradation of cyclins and numerous key cycle proteins. Phosphorylation-cum-proteolytic cellcycle controls originated in posibacteria, but a novel Cdc-6-mediated control over replication initiation evolved in ancestral neomura after histones H3/4 and MCM DNA helicase, replacing eubacterial DnaA/CrtA control; proteolysis by proteasomes that originated in the neomuran/actinobacterial cenancestor replaced eubacterial ClpXP proteolysis. Ancestral eukaryotes evolved origin recognition complexes (ORCs) more complex than the single protein Cdc-6 of archaebacteria, probably because the suddenness of mitotic anaphase (rapidly segregating all parts of chromosomes at once, unlike the temporally separate segregation of origins and the generally single terminus in bacteria) required concerted replication initiation at hundreds of origins, ensuring replication completion and tighter chromosome folding (using extra histones and novel heterochromatin machinery: Cavalier-Smith 2010c) well before mitosis; uniquely in eukaryotes, mitosis demands a temporally discrete $S$ phase. Formerly, only neokaryotes were thought to have ORCs (Cavalier-Smith 2010b), but extremely divergent versions of most constituents are now known in trypanosomes, whose cell-cycle controls are the most divergent within eukaryotes (Li 2012), consistent with eukaryotic rooting between Euglenozoa and neokaryotes (Figs. 1 and 3). Successively more complex controls and checkpoints evolved with novel polo-like and aurora S/T kinases playing multifarious roles in mitosis and cytokinesis and a multiplicity of kinesins evolving to improve spindle assembly and function. Probably all proteins shared by trypanosomes (Li 2012) and opisthokonts evolved before the eukaryote cenancestor. Mitosis (upper panel) was converted to meiosis by two innovations (lower panel): homologous chromosome pairing by the synaptonemal complex and blocking centromeric cohesin digestion at meiosis 1 anaphase, which automatically bypassed cell-cycle resetting caused by anaphase centromere splitting so that the next interphase had no S phase as previously explained (Cavalier-Smith 1981), thereby halving ploidy - the original meiotic function (Cavalier-Smith 2002a, 2010c). (Legend continues on following page.) 


\section{MISUNDERSTANDINGS OF THE NEOMURAN THEORY OF CELL EVOLUTION}

Acceptance that archaebacteria are not a primary domain but evolved from posibacteria is growing. Indel analysis (Skophammer et al. 2006, 2007; Lake et al. 2009; Valas and Bourne $2009,2011)$ supports that and that negibacteria are a derived clade. Palaeontology and multigene trees when critically combined prove that eubacteria historically preceded neomura (Cavalier-Smith 2002b), and eubacteria are about three times as old as neomura (Cavalier-Smith 2006a, 2013a). Thus, there is only one primary "domain" of life: eubacteria (Cavalier-Smith 1987b,c, 2006a,c). Archaebacteria are certainly more recent. The neomura theory is probably cladistically historically correct and coherently logically explains the origins of both eukaryotes and archaebacteria. The transformations it entails are cell-biologically reasonable, selectively comprehensible, and unexplained by alternative ideas. A stimulus through antibiotic warfare among bacteria is likely because penicillin can cause wall loss and many antibiotics target ribosomes and lead to resistance through changes in their structure (Cavalier-Smith 1992). Despite its unequalled explanatory power, the neomuran theory was repeatedly ignored, misunderstood, or misrepresented, but remains unrefuted. Most discoveries since 1987 greatly strengthen its core ideas.

Yet, the lingering dogma/prejudice that archaebacteria are a "primary domain," never with any sound evidence from paleontology or phylogeny, still makes some reluctant to accept that archaebacteria are younger than and evolved from eubacteria. Some still think archaebacteria are ancestors, not sisters of eukaryotes, an idea subconsciously favored by wrongly calling shared features "archaebacterial" not "archaebacteria-like." Some skeptics confuse fundamental tenets of the neomuran / phagotrophy/coevolutionary theory of eukaryote origins with the logically independent, now-disproved idea that some eukaryotes were primitively without mitochondria, proposed earlier when classifying amitochondrial eukaryotes as Archezoa and arguing for the first time (correctly it turned out) that the mitochondrial OM evolved from that of $\alpha$-proteobacteria (Cavalier-Smith 1983a,b). Discoveries of mitochondrial relics in all "Archezoa" showed that no primitively amitochondrial eukaryotes persist, so I abandoned that idea long ago (CavalierSmith 1998, 2002c). That disproved "archezoan hypothesis" concerned the root of the eukaryote tree, not the causes of eukaryogenesis; causal explanation of eukaryogenesis by the probably correct phagotrophy/coevolutionary theory is logically independent, as is the now-associated neomuran interpretation of the phylogenetic relationship between eukaryotes, archaebacteria, and posibacteria, which also I argue is correct. What differs in my present interpretation (Fig. 1) is the root position for (a) eukaryotes, and (b) the whole tree of life. The position of the eukaryotic root between Euglenozoa and neokaryotes (excavates and their descendants) is arguably more secure than previously, being based on a dozen independent reasons, detailed elsewhere (Cavalier-Smith 2010a,c, 2013a), not just one as in previous guesses, and also strongly supported by all prokaryote-rooted ribosomal multiprotein trees using 13, 432 amino-acid positions (Lasek-Nesselquist and Gogarten 2013). An alternative, slightly different position of the eukaryote root within loukozoan excavates, between jakobids and Malawimonas, based solely on mitochondrial protein 42-gene trees (Zhao et al. 2013), risks being somewhat inaccurate because of long-branch artifacts (Shavit et al. 2007).

Figure 5. (Continued) It is unclear whether centromeres evolved from posibacterial plasmid partition proteins associated with GTPase TubZ (Aylett et al. 2010, 2013) or de novo; CENP-A was probably added only in neokaryotes after they diverged from Euglenozoa (Fig. 3) (Cavalier-Smith 2010c). As the text notes, recent evidence suggests that cohesin digestion is not invariably necessary for centriole separation in animals, raising doubt as to the ancestral eukaryotic process. 
Differences in ribosomal RNA sequences that separated the so-called 'three domains' are superficial compared with deep similarities in cell secretory machinery. Shared glycoprotein synthesis involving dolichol phosphate carriers was only one of 16 supporters of the neomuran clade (Cavalier-Smith 1987c); since then at least as many more have been discovered (Cavalier-Smith 2010c); even those few still imagining that archaebacteria and eubacteria evolved separately from a progenote (Martin and Russell 2003) accept neomura as a clade and that archaebacteria and eukaryotes cannot both be "primary domains." Cavalier-Smith (1987c) listed 24 cellular and molecular characters shared by eubacteria and archaebacteria that decisively refuted the progenote hypothesis, proving a direct transition between eubacteria and archaebacteria via a highly developed cellular intermediate with lipid membrane and cytochrome-based membrane-dependent bioenergetics. Such complexity required reliable translation and DNA genomes with efficient replication, repair, and transcription. Subsequently, many others also proved the last common ancestor of life must have been a complex bacterium with well-developed membrane bioenergetics, growth, and division machinery (e.g., Jékely 2006; Lombard et al. 2012b), refuting the entirely untenable idea of separate precellular origins of neomura and eubacteria (Martin and Russell 2003).

Thiergart et al. (2012) tendentiously falsely attributed the branching of only 15 eukaryotic proteins with actinobacteria as the "level of support" for the neomuran theory, seriously misrepresenting its predictions. In fact, their 145 genes branching closest to archaebacteria strongly support it; given equal evolutionary rates and gene losses within euryachaeotes and filarchaeotes, it predicts that an equal number should appear as sister to each subphylum, assuming that they and eukaryotes diverged at virtually the same time; purely by chance, some will group with one and some the other (Cavalier-Smith 2007b). Because crenarchaeote proteins mostly evolve faster and are more often lost, one expects some bias toward euryarchaeotes, exactly as found: 68 trees put eukaryotes closer to filarachaeotes and 77 closer to euryarchaeotes. If eukaryotes evolved substantially more recently than archaebacteria from an ancestor in either archaebacterial subphylum, all 145 trees should put them within that one group. Unwittingly, Thiergart et al. (2012) supplied the strongest evidence yet that archaebacteria cannot be substantially older than eukaryotes, contrary to Martin's assumptions (Martin and Müller 1998; Martin and Russell 2003). Thiergart et al. (2012) misunderstood and misrepresented the neomuran theory by asserting that it originally postulated that eukaryotes evolved from cyanobacteria, citing CavalierSmith (1975). That paper, predating archaebacterial recognition (Woese and Fox 1977) did not propose the neomuran idea.

Very detailed explanations of stepwise origins of endomembranes, nucleus, mitosis, cell cycle, and sex (both mechanisms and selective advantages) in earlier publications (CavalierSmith 2009, 2010c), including detailed criticisms of less plausible alternatives, cannot be adequately summarized here. The rest of this article outlines new insights into bacterial cell evolution that sharpen distinctions between $\mathrm{Ne}$ gibacteria and Posibacteria, making me conclude that Negibacteria and neomura both evolved from Posibacteria, the first cells. This is necessary to explain how bacterial phylogeny maps onto the fossil record, the only direct evidence for evolutionary timing, and thereby perhaps more convincingly than before defend the well-substantiated recency of archaebacteria compared with eubacteria, and simultaneous origin of archaebacteria and eukaryotes from a radically transformed actinobacteria-related posibacterium.

\section{EVOLUTIONARY SIGNIFICANCE OF THE NEGIBACTERIAL CELL ENVELOPE}

The names "Negibacteria" and "Posibacteria," coined to distinguish eubacteria with double or single bounding membranes (Cavalier-Smith 1986, 1987b,c), are phylogenetically more precise than the older "Gram-negative" and "Grampositive" that were evolutionarily confusing because some Posibacteria stain Gram-negatively 
(e.g., mycoplasmas) and some negibacteria (e.g., Deinococcus) stain Gram-positively. I argued that membrane number and biogenesis were fundamentally more important than staining, that OM evolved only once, and was lost at most once since life began. I argue here it was never lost. My key distinction was ignored for decades, partly because Woese's repeated historically inaccurate, naïve tirades against morphology (Woese 1994) led many biochemists to ignore bacterial envelope biology. Confusions caused by such myopia are clearing; renaissance of molecular cell ultrastructural anatomy and membrane biogenesis confirms the fundamental negibacterial/posibacterial dichotomy (excellent reviews: Desvaux et al. 2009; Sutcliffe 2010). Gupta (1998a,b,c) made the same distinction much later, inventing informal terms "diderm" and "monoderm," but astoundingly wrongly asserted that their fundamental phylogenetic distinction was not recognized before 1998 (Gupta 2011). OMs are simple phospholipid bilayers in Hadobacteria (Deinococcus, Thermus) and Thermotogales, which I therefore now place in that phylum, but in all other $\mathrm{Ne}$ gibacteria (as here revised by excluding Chloroflexi), only its inner leaflet is phospholipid (its outer is lipopolysaccharide).

The inner membrane (CM) of negibacteria is homologous with CM of unibacteria in bearing SecYEG channels, SRP receptors, TAT, ABC transporters, type IV secretion, and membranebound respiratory and/or photosynthetic electron transport chains, supporting proton gradients and proton-driven phosphorylation by partially membrane-embedded ATP synthetases. Contrastingly, negibacterial OMs lack all those and are penetrated by large cylindrical proteinaceous pores (porins), allowing free traverse of small molecules, and have $\beta$-barrel proteins, not $\alpha$-helical globular proteins of the $\mathrm{CM}$ and eukaryotic plasma membrane, endomembranes, and peroxisomes. OM $\beta$-barrel proteins move across the $\mathrm{CM}$ via Sec or $\mathrm{ABC}$ carriers, then insert into $\mathrm{OM}$ by using the $\beta$ barrel OM protein Omp85 (attached to the ABC transporter by a "membrane fusion" protein connecting $\mathrm{CM}$ and $\mathrm{OM}$ ). The complexity and conservation of this $\beta$-barrel insertion machin- ery mean that negibacterial OMs had a single origin and were inherited by membrane heredity (Cavalier-Smith 2004) for $>2.5$ billion years, being kept throughout mitochondrial and chloroplast evolution (Cavalier-Smith 2013b). Negibacteria evolved four other secretion mechanisms absent in Unibacteria: types II, V, VI, and VII using different OM porins.

The negibacterial cell plan is outstandingly stable. If the universal tree is rooted in Unibacteria (Fig. 1), the first cell had one membrane, and OMs were never lost in the history of life. If the first cell were negibacterial (Blobel 1980), the OM arose with the first cell (for possible mechanisms, see Cavalier-Smith 2001) and must have been lost by Posibacteria, for which the only plausible mechanism proposed is hypertrophy of murein, thickening the wall enough to break mechanically all contacts between the $\mathrm{CM}$ and $\mathrm{OM}$, preventing $\mathrm{OM}$ biogenesis (Cavalier-Smith 1980). No theory of negibacterial eukaryote origins can be taken seriously without a physically plausible mechanism of OM loss, sufficient reason for firmly rejecting evolution of a phagotrophic wall-free eukaryote from a cyanobacterium (CavalierSmith 1975), ס-proteobacterium (López-García and Moreira 1999), or planctobacterium (similarities between eukaryotes and planctobacteria are superficial misinterpretations: CavalierSmith 2010c; Santarella-Mellwig et al. 2013): Planctomycetes independently lost murein and FtsZ and some acquired tubulins and a kinesin by LGT. Elsewhere, I explained other fatal flaws of the $\delta$-proteobacterium fusion theory (Cavalier-Smith 2010c).

The unrelated extra membrane in the crenarchaeote Ignicoccus without Omp85 machinery (Nather and Rachel 2004) is a trivial convergence irrelevant to the monophyly and uniqueness of negibacteria, contrary to superficial assertions that it invalidates the fundamental importance, evolutionary stability, and uniqueness of negibacterial architecture, and complex biogenesis. More important exceptions to the usual posibacterial body plan are Mycobacteria, actinobacteria that probably convergently with Negibacteria evolved an OM. Mycobacteria have a very thick murein wall, fur- 
nished with posibacterial sortases for lipoprotein secretion like related teichobacteria (Cavalier-Smith 2006a); their OM is a lipid bilayer, not phospholipid, but outer leaflet glycolipid and inner mycolic acid linked by arabinogalactan to underlying peptidoglycan (Silhavy et al. 2010). Presumably, it originated by secretion across the wall like the waterproofing lipid cuticles of land plants and insects. The key biophysical problem in its origin was permeabilizing it to hydrophilic molecules: by $\beta$-barrel porins (Song et al. 2008) —but did these originate independently of negibacterial porins or via LGT from them? I predict that Omp85 insertion machinery is absent and consider them Posibacteria.

Theories of negibacterial origin generate their OM contrastingly: from endospore-forming posibacteria (Endobacteria) by prespore engulfment by its sister cell (Dawes 1981); by folding up an inside-outcell with external genes and ribosomes to form the first cell (Blobel 1980). They give radically different answers to the fundamental question: Did posibacteria precede negibacteria (Fig. 1), or vice versa (Blobel 1980)? Neomura remain a clade in either view. Because Blobel's idea offered a way of evolving cells unhampered by phospholipid bilayer impermeability to nucleotides and amino acids, I initially preferred it (Cavalier-Smith 1987b, 2001). However, that problem is now circumvented because FAs probably originally were shorter than today (Budin et al. 2009, 2012), making a single membrane more plausible for the first cell because it avoids Blobel's sealingoff gastruloid phase, which the OM biogenesis complexity now revealed makes unlikely. Recent endobacterial discoveries also support Dawes's idea, although some (Errington 2013) overlook his priority. Overall, a unibacterial root for prokaryotes now seems mechanistically simpler for envelope evolution.

\section{GREEN BACTERIA AND THE ORIGIN OF LIFE}

Chloroflexi (chlorobacteria: non-sulfur green bacteria plus non-photosynthetic relatives) are not Negibacteria, despite their Gram-negative staining and some electron micrographs suggesting an OM, but divergent Posibacteria (Sutcliffe 2011). A long-running mistake considered them negibacteria (Cavalier-Smith 1987b,c, 1991a,b, 1992, 2002b, 2006a,c, 2010a). Their early 16S rDNA grouping with Hadobacteria (oddly still believed by Woese 2013) seems to have been a misleading long-branch problem. A 31-protein tree (Ward et al. 2009) groups them with Teichobacteria and Actinobacteria (Fig. 3). Transfer of Chloroflexi to Posibacteria makes Negibacteria coterminous with Omp85 OM biogenesis machinery, more sharply defining the subkingdom. Accepting Chloroflexi as Posibacteria removes the polarization wrongly placing them at the base of Negibacteria (Cavalier-Smith 2006c) but does not alter earlier arguments for their being the most primitive of all bacteria.

Indeed, a novel aerobic green photoheterotrophic bacterium Candidatus Chloracidobacterium (Bryant et al. 2007), a Negibacterium in deep-branching class Acidobacteria of Proteobacteria sensu (Cavalier-Smith 2002b), reinforces the view that green bacteria were at the root of the universal tree (Cavalier-Smith 1985, 1991a,b, 1992). Because Chloracidobacterium has chlorosomes and a type I photosynthetic reaction center, like Chloroflexi and Chlorobi (green sulfur bacteria: negibacteria) (Garcia Costas et al. 2011; Tsukatani et al. 2012), and Acidobacteria are sisters to purple proteobacteria and their colorless relatives (Ward et al. 2009), the lineage connecting negibacteria and posibacteria clearly had chlorosomes and type I reaction centers, as also did that joining Chlorobi to the base of Proteobacteria, assuming vertical inheritance of photosynthesis. Congruence of type I reaction-center (Bryant et al. 2007) and 31-protein (Ward et al. 2009) trees contradicts invoking photosynthetic machinery LGT to negate that.

A universal root in Negibacteria, which a flagellar polarization argument favored (Cavalier-Smith 2006c), would most plausibly be within Gracilicutes between Chlorobi and Chloracidobacterium. Were it in Posibacteria as I now prefer (Fig. 3) and some indels suggest (Skophammer et al. 2007), it is probably be- 
tween Chloroflexi and Teichobacteria (which include the green chlorosome-lacking photoheterotrophic Heliobacteria as well as heterotrophic Bacillales and Clostridiales), and LGT from gracilicute Negibacteria presumably gave Posibacteria flagella. Thus, ancestral cells were probably photosynthetic green bacteria, whether the universal root is in Posibacteria or Negibacteria. Unless this root is within Gracilicutes, the unique purple bacterial photosynthetic machinery must have green bacterial ancestry, as probably do cyanobacterial photosystems. The 31-protein tree and posibacterial root together fit conclusions from photosystem evolution that heliobacterial photosynthesis is the most primitive, followed by Chloroflexi, then Cyanobacteria, gracilicute photosynthesis being more derived (Gupta 2012). If cell lineages diverged as in Figure 3, gene duplications probably created photosystem II (Sousa et al. 2013) in the common ancestor of Cyanobacteria and Gracilicutes, system II being lost by Chlorobi and Chloracidobacterium (and type I reaction centers by Proteobacteria); galactolipid synthesis for photosynthetic membranes probably originated in green posibacteria (monogalactosyldiacylglycerol synthase homologs are conserved throughout posibacteria) (Yuzawa et al. 2012). Multiple losses during photosynthetic diversification were probably more and LGT less frequent than many assume. Whether the first cell was a Heliobacterium-like posibacterium (most likely) or Chlorobium-like Negibacterium, it lacked flagella and RuBisCo.

\section{INTEGRATING MULTIGENE SEQUENCE TREES AND FOSSIL DATA FOR REAL TIMING OF CELL MEGAEVOLUTION}

The eubacterial radiation is extremely bush-like with very little basal resolution even on multigene trees (Battistuzzi et al. 2004; Ciccarelli et al. 2006). The 25-protein tree of Battistuzzi et al. (2004) showed clear bipartition between Gracilicutes (phyla Spirochaetae, Proteobacteria, Sphingobacteria, Planctobacteria, including the monophyly of each except Planctobacteria) and all other bacteria, but incorrectly placed cyanobacteria and Deinococci (with Thermus constituting the phylum Hadobacteria) within Posibacteria, suggesting that they might be more closely related to Posibacteria than are Gracilicutes. The 31-protein tree of Ward et al. (2009) groups Hadobacteria (bootstrap support $100 \%$ for their monophyly) and Thermotoga/Aquifex as sisters with $69 \%$ support, but wrongly places Cyanobacteria and Fusobacteria deeply within Posibacteria (insignificant $12 \%$ support); that tree showed monophyly of Gracilicutes (81\%, support), 97\% support for monophyly of Planctobacteria, $87 \%$ for Proteobacteria sensu Cavalier-Smith (2002b) (including Acidobacteria), and $100 \%$ for Spirochaetae and for Sphingobacteria (Chlorobi + Bacteriodetes and relatives), and for the latter two being sisters. From cell evolution perspectives, that multigene tree is the best I know for Eubacteria.

To eliminate potential LGT problems, Bapteste et al. (2008) selected 22 compatible markers from 31, unfortunately with narrower taxonomic sampling and all branching with $<50 \%$ support unwisely collapsed; they found just four eubacterial clades: Gracilicutes (72\%), Endobacteria (lowGC Posibacteria: 58\%), both with major anaerobic and aerobic lineages, and two aerobic clades, each with $100 \%$ support (Cyanobacteria, Actinobacteria). Higher support for aerobic clades is because they branch less deeply than mixed aerobic/anaerobic clades, with a longish bare stem. That contrast has a simple evolutionary explanation, their respective radiation timings: crown cyanobacteria arguably radiated near the time of the great oxygenation event they caused (2.4 Gy ago), whereas actinobacteria (with proportionately longer bare stem) radiated somewhat later, after oxygenation enabled their aerobic heterotrophy. In contrast, Gracilicutes and Endobacteria, with anoxygenic photosynthesizers and numerous anaerobic heterotrophs or chemotrophs, radiated earlier, probably $>2.7$ Gy ago, but $<3.5$ Gy ago. Stem lineages of both aerobic groups were probably anaerobes; I suggest anaerobic green bacteria for cyanobacteria and anaerobic heterotrophic endobacteria for actinobacteria. Mycoplasmas are sisters to Bacillales within Teichobacteria, confirming their murein loss; they have longer branches than any other Posibacte- 
ria, showing that wall loss and/or genome miniaturization somewhat released their proteins from stabilizing selection, analogously to the elevated evolutionary rates of neomura. Evolutionary rates in Bapteste et al. (2008) are similar within other major clades, slightly greater in Gracilicutes than Cyanobacteria or Posibacteria (Posibacteria apparently a weakly supported clade collapsed into two during figure preparation). Applying a crude evolutionary clock to eubacteria indicates that cyanobacteria initially radiated almost contemporaneously with purple bacteria. Although backward-extrapolating clock estimates are problematic because they do not allow for quantum evolution that can inflate ages (Cavalier-Smith 2002b) or for systematic differences between rates across domains and phyla, Feng et al. (1997) estimated 2.1-2.5 Gy ago for the date of the Posibacteria/ Cyanobacteria/other Negibacteria radiation, in surprisingly close harmony with the robust palaeontological date of $\sim 2.4$ Gy ago for the great atmospheric oxidation event (Schirrmeister et al. 2013).

Eukaryotes cannot have originated significantly before $\alpha$-proteobacteria, which must be younger than purple bacteria generally. The $\alpha$-proteobacterial radiation on the 22 -gene tree is about half as old as for purple bacteria collectively. That implied age of $\sim 1.25$ Gy ago must be somewhat too low because of limited taxon sampling. From the more taxon-rich 191genome tree of Ciccarelli et al. (2006), the same argument gives a maximal eukaryote age of $\sim 1.8$ Gy ago. Given the resolution within joint mitochondrial $/ \alpha$-proteobacterial gene trees (Derelle and Lang 2012; Zhao et al. 2013), mitochondria probably did not arise from the first $\alpha$-proteobacteria, but are probably $<80 \%$ as old as $\alpha$-proteobacteria, perhaps younger still. That gives $\sim 1.44 \mathrm{~Gy}$ ago as a reasonable upper limit for eukaryote age, close to the oldest fossils (1.45 Gy ago) that several palaeontologists regard as eukaryotic (Javaux et al. 2001), although I consider them more likely all misinterpreted bacteria (Cavalier-Smith 2006a). Independent estimates of minimum eukaryote age from the morphological fossil record and eukaryote multigene trees (Cavalier-Smith 2013a) of $\sim 1.2 \pm 0.25$ Gyare congruent and surprisingly close. These estimates bracket the origin of eukaryotes between 0.95 and 1.45 Gy ago, making them $2.4-3.7 \times$ younger than stem eubacteria ( $2.5 \mathrm{~Gy})$, although possibly no more than twice as young as the probably explosive crown eubacterial radiation (here estimated as $\sim 2.7 \mathrm{~Gy}$ ago). The archaebacteria branch is far longer than all eubacterial clades: more than three times as long as that of most eubacteria and about five times longer than cyanobacteria. Because cyanobacteria are $>2.4$ Gy old (Schirrmeister et al. 2013), more likely 2.7 Gy (Bosak et al. 2009, 2012; Petroff et al. 2010; Bosak et al. 2012), that date objectively calibrates the mean length of crown cyanobacterial branches; because the stem connecting the base of crown eubacteria to the base of crown archaebacteria is just over five times longer, it would represent $12 \mathrm{~Gy}$ of evolution (conservatively assuming $2.4 \mathrm{~Gy}$ : $2.6 \times$ the 4.6 Gy age of the Earth and $3.4 \times$ the age of all life: $3.5 \mathrm{~Gy}$ ) if these 22 proteins were then evolving at the same rate as in cyanobacteria for the past 2.4 Gy. Likewise, crown Archaebacterial branches are substantially longer than crown cyanobacterial ones and would represent $\sim 6.4$ Gy of evolution; stem plus crown would represent $18 \mathrm{~Gy}$, greater than the $13 \mathrm{~Gy}$ age of the universe. From these necessarily underestimates, the logically inescapable conclusion is that these proteins evolved substantially faster in crown eukaryotes and crown archaebacteria than in eubacteria, and that neomuran stem lengths on most sequence trees are hugely inflated by quantum evolution, causing false conclusions about timing if that is overlooked (e.g., Doolittle 1995).

That gross rate inequality invalidates midpoint rooting of prokaryotic distance networks (using subsets of gene families from 191 genomes) by Dagan et al. (2010). Their favorite network (Fig. 5) shows the archaebacteria stem much longer than the whole cyanobacterial branch and stem plus crown $\sim 3 \times$ longer, so their statistical argument for uniform evolutionary rates is fallacious and their rooting no better than "reading chicken entrails," to use the apposite phrase introduced by the senior author (Graur and Martin 2004). Dagan et al. falsely 
claim that I "dismiss molecular data" "where convenient” by invoking quantum evolution. On the contrary, I extensively used molecular data combined with objective fossil evidence on timing, which proved the reality of quantum evolution in many molecules and disproved their gradualist assumptions. They selectively interpret fossil evidence that provides no hard evidence that archaebacteria are older than $1.5 \mathrm{~Gy}$, notwithstanding earlier carbon isotope ratios overconfidently interpreted as evidence for archaebacterial methanogenesis (CavalierSmith 2006a). Their Figure 4C net for the gene family tranche conserved $35 \%-40 \%$ clearly bipartitions Negibacteria from Unibacteria.

Compared with the sophisticated multigene trees discussed above, the three-domain singlegene rDNA trees shown by Pace (2009), Woese (2013), and Fournier and Gogarten (2010) are archaic, of only historical interest representing a pioneering but primitive three-decades-old phase of phylogenetics, suitable only for Pace's T-shirts. In all, and even the technically better but taxonomically undersampled concatenated rDNA trees of Williams et al. (2012), the branching within eukaryotes is certainly substantially wrong (judged by numerous multigene trees based on many scores of proteins), that within eubacteria completely unresolved bush, and assumptions of rooting probably erroneous, naïvely relying on probably artifactual paralog duplicate trees. Referring to them as the universal tree of life (Pace 2009) is more confusing than enlightening.

The trees based on 34 universal ribosomal proteins in Lasek and Gogarten (2013) are much better in emphasizing a two-domain structure (eubacteria versus neomura; neomura share 30 new proteins entirely absent in the ribosomally simpler and older eubacteria) and having an almost correct branching order within eukaryotes (their root constantly between Euglenozoa and neokaryotes). They have no basal resolution within eubacteria, as expected if the universal root is among them followed by extremely rapid radiation and or saturation effects. Williams et al. $(2012,2013,2014)$, though accepting that the three primary domains idea is wrong (they correctly treat eukaryotes as derived, not primary) and that neomura are a clade (oddly without using that name), still argue for two primary domains, mistakenly viewing eubacteria as a clade and regarding eubacteria and archaebacteria both as primary domains. I suspect that widespread failure to accept eubacteria alone as the single primary domain of life, as I have consistently argued since 1987, owes more to the mistaken dogmas briefly discussed below than to the evidence, which is admittedly hard for many specialists to evaluate as it depends on critical integration of palaeontology and neontology, both phylogenetics and molecular and especially cell biology of both bacteria and eukaryotes, as well as critical judgments about the mechanistic and selective plausibility of the various transitions theoretically possible among the five major cell types shown in Figure 1.

\section{METHODOLOGICAL BIASES AND MOLECULAR CHRONOMETRIC MYTHS}

It is important to note that even if there is no resolution whatever in input data for sequence trees, as would be the case if (as I argue) eukaryotes, filarchaeotes, and euryarchaeotes diverged essentially simultaneously, phylogenetic algorithms can be biased to introduce apparently strong support for meaningless conclusions (Yang 2007). Too often sequence trees are treated as factual data, rather than indirect inferences based on oversimplified evolutionary assumptions, because they always inevitably are, and given excessive emphasis compared with other evolutionary evidence, morphological, cell biological and palaeontological; all kinds of evidence must be treated critically and integrated if we are to solve such difficult historical problems.

The very long eukaryotic stems in the 29protein trees of Williams et al. (2012), strongly dependent on ribosome-associated proteins, are attributable substantially to exceptionally rapid quantum evolution consequential on the origin of the nucleus, as explained previously (Cavalier-Smith 2002b); as also explained there, similar quantum evolution during the neomuran revolution in SRP cotranslational secretion may partially explain the comparably 
long stem separating eubacteria and Neomura, whose length (whatever its causes) arguably virtually ensures a Shavit et al. (2007) type of artifact, failing to group neomura with the single (!) included posibacterium. Neither of these long stems accurately reflects long evolutionary times, but rapid quantum evolutionary stretching; proteins chosen for many three-domain trees are the least clock-like of all and are biased toward the minority that clearly differentiate archaebacteria and eubacteria (Cavalier-Smith 2002b). The two posibacterial lineages (Actinobacteria, Chloroflexi) that are closest to Neomura on classical rRNA trees (Woese 2013) and closer than any sampled were not even included by Williams et al. (2012), and the latter (the closest) was absent from Fournier and Gogarten (2010), making both poor tests of neomuran relationships.

One need only look at the wildly high evolutionary rates of $16 \mathrm{~S}$ rDNA in microsporidia that led to their being misconstrued as the earliest eukaryotes (Vossbrinck et al. 1987), when they really are advanced derivatives of Choanozoa of comparable recency to fungi (CavalierSmith 2013a; James et al. 2013), or of chloroplast $16 \mathrm{~S}$ rDNA in dinoflagellates (Zhang et al. 2000), to appreciate the absurdity of the claim for small-subunit ribosomal rRNA as a molecular chronometer, or the falseness of the assumption that big changes in its structure must necessarily be ancient (Woese and Fox 1977). The whole Woesian "three-domain" perspective was biased and fundamentally misled by his profoundly mistaken assertion that rRNA is a "molecular chronometer"; the precise opposite is true, rRNA being possibly the least clock-like of all molecules in evolutionary rates. The extraordinarily elongated branch lengths for Microsporidia (James et al. 2013) and for an independently ultrarapidly evolving haplosporidian, the rhizarian parasite Mikrocytos mackini (Burki et al. 2013), on multigene trees emphasize that no proteins universally evolve in a uniform clock-like manner. One must use fossils and genuine atomic decay clocks in igneous rocks for objective timing, as Woese never did.

The foundation of the three-domain dogma is excessively narrow, depending mainly (not quite exclusively) on ribosome-related characters subject to temporally misleading quantumevolutionary biases during the neomuran revolution and eukaryogenesis (Cavalier-Smith 1981,1987 c, 2002b). In a survey of 80 universally conserved proteins, Harris et al. (2003) found that of the 50 whose trees agreed with that of rDNA in showing archaebacteria and eukaryotes as sisters, all except two transcriptional and four DNA replication/repair genes were ribosome-associated; none of the 30 proteins that disagreed with their rRNA tree were ribosome-associated. They unwisely dismissed all 28 of those showing phylogenetically intermixed eubacteria and neomura from serious consideration as likely to have undergone LGT at some stage, downplaying and almost ignoring the alternative reasonable explanation that metabolic genes generally did not undergo quantum evolution during the neomuran revolution, and therefore lack the stretched stem that through grossly violating molecular-clock assumptions greatly enhances ribosome-related sequence tree evidence for the monophyly of neomura (see Cavalier-Smith 2002b). In fact, both their and my explanations of this important, sub-carpet-swept, incongruence between metabolic and ribosomal genes are probably correct for different branches; I suspect that inherently poor resolution caused by lack of resolution-enhancing quantum evolution (combined with archaebacteria actually being younger than their eubacterial ancestors) is the major reason and LGT the minor one.

Two more open-minded devotees of the Woesian perspective (Doolittle and Zhaxybayeva 2013) emphasize that "a much larger number [than the few informational genes that differentiate archaebacteria and eubacteria], many hundreds, of 'operational' genes make up a shared resource that is common to Bacteria and Archaea" and that all prokaryotes have "a vast shared pool of genes encoding diverse metabolic functions seldom if ever used by eukaryotes." They candidly admit that for "metabolism, regulation, population genetics, and ecology... without knowing in advance it would, in many instances, be hard to say whether a particular published paper on these topics 
had a bacterium or an archaeon as its study object." Differences between archaebacteria and eubacteria have been grossly exaggerated. Doolittle and Zhaxybayeva (2013) cogently argue that the notion of a fundamental dichotomy between ancestral prokaryotes and derived eukaryotes in cell organization remains perfectly valid and evolutionarily sound, despite overconfident and superficial propaganda against it from archaeaologists, mainly Pace. They also highlight the tacit refusal by Woese and Pace to recognize neomura as a clade, a failure that Doolittle and Zhaxybayeva (2013) emphasize can be understood only in sociological, rhetorical, or propagandistic, not scientific terms, because it would entail explicitly admitting the undoubted fact that the idea of three primary domains was simply wrong. (So is the idea of two primary domains, which Doolittle and Zhaxybayeva still espouse.) They equally overlooked the key concept of Negibacteria; neither Woese (2013) nor Pace (2009) (nor even Doolittle and Zhaxybayeva) mentions the two-membrane character of their envelope, vital for understanding bacterial evolution and eukaryogenesis.

As far as I know, Woese and Pace never cited any of my papers or attempted to refute their arguments; under a tree in Cold Spring Harbor in 1987, George Fox (coinventor of archaebacteria) told me not to send my first neomuran paper to Woese, despite complimenting its "many good arguments," because "he would not bother to read it." Even his swansong (Woese 2013) restricted discussion of the archaebacteria-eukaryote relationship to one extremely superficial paragraph that merely (rightly) rejected the ideas of Hyman Hartman and Martin and Russell (2003) (sadly, Woese's own attempts at "explaining" cell evolutionlatterly by vague invocation of rampant LGTwere devoid of significant cell biological content or logic). His assertion that "Evolution does not proceed by suddenly and drastically altering a given cell design (at least a fairly advanced one)" could hardly be more wrong for eukaryogenesis; but that prejudice simply explains why he was unprepared even to contemplate the possibility of a derived nature for archaebacteria, as some other influential and otherwise good scientists sadly still are. Nonetheless, Woese (2013) greatly pleased me by advocating "bacteriology" not "microbiology" for the whole science of prokaryotes (a name he also used without objection, unlike Pace), and using "bacteria" in his text exactly as I long have to refer to all prokaryotes, including "archaea," and reinstating both "eubacteria" and "eukaryotes" (but his figure contradictorily used "bacteria" and pointless "eukarya")_-welcome partial recantation of earlier nomenclatural unwisdom (Woese et al. 1990). Likewise, his fundamental misinterpretations of the tree of life and the evolutionary significance of archaebacteria that so severely misled a generation of researchers will not maintain their distorting stranglehold over phylogenetic thinking, if the rising generation of vigorous, less-prejudiced younger researchers demands proper emphasis on cell-biological, palaeontological, and 3D ultrastructural and crystallographical evidence of molecular morphology (Jékely 2006, 2008; Valas and Bourne 2009; Keeling 2013), in addition to the limited presently dominant one-dimensionality of sequences, when reconstructing the history of life. Morphology at all levels underlies evolution: electrical attractions and repulsions between different shapes vivify cells, not mathematical abstractions like sequences.

Doolittle (2000), especially, has much exaggerated the degree to which LGT confuses the tree of life, best seen as an organismal tree based on predominantly vertically inherited cell lineages (Fig. 1), not a multigene tree. Even in prokaryotes, cell lineages devoid of anastomoses by sex or symbiogenesis were simply tree-like for 2 billion years before eukaryotes.

Vertical inheritance of distinctive prokaryotic cell structures and integrated cell cycles was the phylogenetic framework within which LGT fiddled around with relatively restricted metabolic details, creating a genic but not organismal web: both by near-neutral replacements of roughly equivalent enzymes catalyzing a standard reaction and by truly novel acquisition of adaptively valuable, phylogenetically distant catalysts. But these gene-by-gene transfers do not alter the fact that the basic differences in cell structure between eubacterial phyla like 
Cyanobacteria, Spirochaetae, Posibacteria, and Proteobacteria have been stable for billions of years despite LGT, as has their distinctiveness from Archaebacteria for more than a billion, and can be used in interpreting bacterial organismal megaevolution (Fig. 3) in much the same way as we can reliably and meaningfully for eukaryotes despite the temporarily confusing effects of sex and symbiogenesis (although LGT, greater substitutional saturation over the longer timescale, and paucity of ultrastructural complexity do make it harder for the truly ancient eubacteria than for the younger neomura). On the neomuran interpretation, the primary phase of "progressive Darwinian evolution" that improved the basic machinery of life after cells first evolved, as speculatively discussed by Doolittle and Zhaxybayeva (2013) and hordes of others (including me: Cavalier-Smith 1987b, 2001) in the past three decades, took place not in the stem connecting neomura and eubacteria, as they and so many others wrongly assume, but much earlier in the stem eubacteria necessarily missing from sequence trees, during the early Archaean period 3.5-2.7 Gy ago (which does not mean the period when "Archaea" lived-they are purely Protoerozoic [mid and late, not even early] and Phanerozoic bacteria). Some of these speculations are sensible if applied to stem bacteria but totally misleading if applied to stem neomura, whose evolution we can reliably infer by critical and multievidencial comparative biology. Contrary to pervasive, often dogmatic, misconceptions stemming primarily from Woese's chronometric myth and aversion to accepting megaevolutionary change in advanced cells, the last universal common ancestor of life (LUCA) did not lie on the stem connecting neomura and eubacteria, but within the eubacterial radiation.

The derived nature and recency of archaebacteria have been long concealed by pervasive biases in citing or interpreting contradictory paralog duplicate trees, as explained previously (Cavalier-Smith 2002b, 2006c); numerous paralog trees, which place the root within eubacteria, as I consider correct, and thus contradict the Woesian paradigm, are either ignored or dismissed by vaguely invoking LGT (Zhaxy- bayeva et al. 2005), and those that agree, which are probably dominated by misleading longbranch artifacts (Cavalier-Smith 2006c), are cited as support! Trees that place Archaebacteria closer to Posibacteria than to Negibacteria, in concordance with neomuran theory, are too lightly dismissed as implying LGT (e.g., Feng et al. 1997). The seemingly objective but probably artifactual rooting by the first paralog duplicate trees (Gogarten et al. 1989; Iwabe et al. 1989) eclipsed my still-cogent earlier arguments for a eubacterial root (Cavalier-Smith 1987c), and subsequent dogma and uncritical inertia allowed Doolittle and Zhaxybayeva (2013) to write that "most biologists today" would believe one of their Figures $2.3 \mathrm{f}-\mathrm{h}$, which all wrongly (as argued here and since 1987) show archaebacteria as old as eubacteria. Contrary to that widely held assumption there is no historically convincing evidence for archaebacteria being as old as Eubacteria; instead, their Figures 2.3b,d (elaborated in my Figs. 1 and 3) are probably correct for reasons summarized above. Another attempt at rooting the universal tree using amino acid composition biases depends on several highly questionable assumptions (Fournier and Gogarten 2010); from my perspective, their data simply indicate that there was a bigger change in ribosomal protein composition during the neomuran revolution than during either eukaryogenesis or the origin of archaebacteria, and fall short of proving where the root lies.

Two other biases prejudice bioinformatics interpretations: the prevalence of gene loss (underestimating it inflates LGT estimates and grossly deflates estimates in the number of genes present in the cenancestor of each domain); and the prevalence in megaevolution like eukaryogenesis of radical gene evolution beyond bioinformatics recognition, which led to hugely wrong conclusions about the relative contributions of neomura and $\alpha$-proteobacteria to the eukaryotic chimera (see Cavalier-Smith 2007b).

I must stress that if more convincing evidence than now exists were to appear and establish that eukaryotes are really derived from archaebacteria (Williams et al. 2012, 2013, 2014), contrary to my arguments that they are sisters, that would prove even more strongly that neo- 
mura are a clade. But it would not provide any evidence that archaebacteria are a primary domain as old as eubacteria. Nor would it alter the essential cell biological or selective bases for the major innovations in cell biology during eukaryogenesis discussed here. It would just make a mechanistically rather trivial change in the precise phylogenetic origins of some of the precursor proteins for these dramatic megaevolutionary changes, and introduce a slightly greater time interval between the origin of eukaryotes and archaebacteria than I have assumed. The most innovative core features of my cell evolutionary arguments for the secondary origins of both groups would remain valid.

\section{CONCLUDING REMARKS}

Understanding eukaryote origins requires balanced synthesis of cell biology, palaeontology, and phylogeny into a complete logically consistent picture, here outlined. Partial approaches from single perspectives spawned many oversimplified or unnecessarily complex ideas, often biasing interpretations or obscuring the basic simplicity of cell history. Especially difficult has been determining the root of the tree for all life and eukaryotes (Figs. 1 and 3), essential for deducing phenotypes for early eukaryotes and their ancestors and sound reasoning about eukaryogenesis. Errors ensure false interpretations, hard to correct because tree-root positions are often taken as "obviously true" when interpreting other data. We must be ready to change conclusions radically if new evidence or insights demand it.

\section{REFERENCES}

Adams DW, Errington J. 2009. Bacterial cell division: Assembly, maintenance and disassembly of the $\mathrm{Z}$ ring. Nat Rev Microbiol 7: 642-653.

Aylett CH, Wang Q, Michie KA, Amos LA, Lowe J. 2010. Filament structure of bacterial tubulin homologue TubZ. Proc Natl Acad Sci 107: 19766-19771.

Aylett CH, Izore T, Amos LA, Lowe J. 2013. Structure of the tubulin/FtsZ-like protein TubZ from Pseudomonas bacteriophage $\phi K Z$. J Mol Biol 425: 2164-2173.

Bapteste E, Susko E, Leigh J, Ruiz-Trillo I, Bucknam J, Doolittle WF. 2008. Alternative methods for concatenation of core genes indicate a lack of resolution in deep nodes of the prokaryotic phylogeny. Mol Biol Evol 25: 83-91.
Barber CF, Heuser T, Carbajal-Gonzalez BI, Botchkarev VV Jr, Nicastro D. 2012. Three-dimensional structure of the radial spokes reveals heterogeneity and interactions with dyneins in Chlamydomonas flagella. Mol Biol Cell 23: $111-120$.

Barns SM, Delwiche CF, Palmer JD, Pace NR. 1996. Perspectives on archaeal diversity, thermophily and monophyly from environmental rRNA sequences. Proc Natl Acad Sci 93: 9188-9193.

Battistuzzi FU, Feijao A, Hedges SB. 2004. A genomic timescale of prokaryote evolution: Insights into the origin of methanogenesis, phototrophy, and the colonization of land. BMC Evol Biol 4: 44.

Bernander R, Lundgren M, Ettema TJ. 2010. Comparative and functional analysis of the archaeal cell cycle. Cell Cycle 9: 794-806.

Blobel G. 1980. Intracellular protein topogenesis. Proc Natl Acad Sci 77: 1496-1500.

Bosak T, Liang B, Sim MS, Petroff AP. 2009. Morphological record of oxygenic photosynthesis in conical stromatolites. Proc Natl Acad Sci 106: 10939-10943.

Bosak T, Liang B, Wu TD, Templer SP, Evans A, Vali H, Guerquin-Kern JL, Klepac-Ceraj V, Sim MS, Mui J. 2012. Cyanobacterial diversity and activity in modern conical microbialites. Geobiology 10: 384-401.

Bower R, Tritschler D, Vanderwaal K, Perrone CA, Mueller J, Fox L, Sale WS, Porter ME. 2013. The N-DRC forms a conserved biochemical complex that maintains outer doublet alignment and limits microtubule sliding in motile axonemes. Mol Biol Cell 24: 1134-1152.

Brochier-Armanet C, Boussau B, Gribaldo S, Forterre P. 2008. Mesophilic Crenarchaeota: Proposal for a third archaeal phylum, the Thaumarchaeota. Nat Rev Microbiol 6: $245-252$.

Brugerolle G. 1992. Flagellar apparatus duplication and partition, flagellar transformation during division in Entosiphon sulcatum. BioSystems 28: 203-209.

Bryant DA, Costas AM, Maresca JA, Chew AG, Klatt CG, Bateson MM, Tallon LJ, Hostetler J, Nelson WC, Heidelberg JF, et al. 2007. Candidatus Chloracidobacterium thermophilum: An aerobic phototrophic acidobacterium. Science 317: 523-526.

Budin I, Bruckner RJ, Szostak JW. 2009. Formation of protocell-like vesicles in a thermal diffusion column. J Am Chem Soc 131: 9628-9629.

Budin I, Debnath A, Szostak JW. 2012. Concentration-driven growth of model protocell membranes. J Am Chem Soc 134: 20812-20819.

Buisson J, Chenouard N, Lagache T, Blisnick T, Olivo-Marin JC, Bastin P. 2013. Intraflagellar transport proteins cycle between the flagellum and its base. J Cell Sci 126: $327-$ 338.

Burki F, Corradi N, Sierra R, Pawlowski J, Meyer GR, Abbott CL, Keeling PJ. 2013. Phylogenomics of the intracellular parasite Mikrocytos mackini reveals evidence for a mitosome in Rhizaria. Curr Biol 23: 1541-1547.

Buske PJ, Levin PA. 2013. A flexible C-terminal linker is required for proper FtsZ assembly in vitro and cytokinetic ring formation in vivo. Mol Microbiol 89: 249-263. 
T. Cavalier-Smith

Cabral G, Sans SS, Cowan CR, Dammermann A. 2013. Multiple mechanisms contribute to centriole separation in C. elegans. Curr Biol 23: 1380-1387.

Carbajal-Gonzalez BI, Heuser T, Fu X, Lin J, Smith BW, Mitchell DR, Nicastro D. 2013. Conserved structural motifs in the central pair complex of eukaryotic flagella. Cytoskeleton (Hoboken) 70: 101-120.

Carvalho-Santos Z, Machado P, Branco P, Tavares-Cadete F, Rodrigues-Martins A, Pereira-Leal JB, Bettencourt-Dias M. 2010. Stepwise evolution of the centriole-assembly pathway. J Cell Sci 123: 1414-1426.

Carvalho-Santos Z, Azimzadeh J, Pereira-Leal JB, Bettencourt-Dias M. 2011. Evolution: Tracing the origins of centrioles, cilia, and flagella. J Cell Biol 194: 165-175.

Cavalier-Smith T. 1974. Basal body and flagellar development during the vegetative cell cycle and the sexual cycle of Chlamydomonas reinhardii. J Cell Sci 16: 529-556.

Cavalier-Smith T. 1975. The origin of nuclei and of eukaryotic cells. Nature 256: 463-468.

Cavalier-Smith T. 1978a. The evolutionary origin and phylogeny of microtubules, mitotic spindles and eukaryote flagella. BioSystems 10: 93-114.

Cavalier-Smith T. 1978b. Nuclear volume control by nucleoskeletal DNA, selection for cell volume and cell growth rate, and the solution of the DNA C-value paradox. $J$ Cell Sci 34: 247-278.

Cavalier-Smith T. 1980. Cell compartmentation and the origin of eukaryote membranous organelles. In Endocytobiology: Endosymbiosis and cell biology, a synthesis of recent research (ed. Schwemmler W, Schenk HEA), pp. 893916. de Gruyter, Berlin.

Cavalier-Smith T. 1981. The origin and early evolution of the eukaryotic cell. In Molecular and cellular aspects of microbial evolution (ed. Carlile MJ, et al.), pp. 33-84. Cambridge University Press, Cambridge.

Cavalier-Smith T. 1982. The evolutionary origin and phylogeny of eukaryote flagella. In prokaryotic and eukaryotic flagella 35th symposium of the society of experimental biology (ed. Amos WB, Duckett JG), pp. 465-493. Cambridge University Press, Cambridge.

Cavalier-Smith T. 1983a. A 6-kingdom classification and a unified phylogeny. In Endocytobiology II (ed. Schwemmler W, Schenk HEA), pp. 1027-1034. de Gruyter, Berlin.

Cavalier-Smith T. 1983b. Endosymbiotic origin of the mitochondrial envelope. In Endocytobiology II (ed. Schwemmler W, Schenk HEA), pp. 265-279. de Gruyter, Berlin.

Cavalier-Smith T. 1985. Introduction: The evolutionary significance of genome size. In The evolution of genome size (ed. Cavalier-Smith T), pp. 1-36. Wiley, Chichester, UK.

Cavalier-Smith T. 1986. The kingdoms of organisms. Nature 324: 416-417.

Cavalier-Smith T. 1987a. Bacterial DNA segregation: Its motors and positional control. J Theor Biol 127: 361-372.

Cavalier-Smith T. 1987b. The origin of cells: A symbiosis between genes, catalysts, and membranes. Cold Spring Harb Symp Quant Biol 52: 805-824.

Cavalier-Smith T. 1987c. The origin of eukaryotic and archaebacterial cells. Ann NY Acad Sci 503: 17-54.
Cavalier-Smith T. 1991a. The evolution of cells. In Evolution of life (ed. Osawa S, Honjo T), pp. 271-304. Springer, Berlin.

Cavalier-Smith T. 1991b. The evolution of prokaryotic and eukaryotic cells. In Fundamentals of medical cell biology (ed. Bittar GE), Vol. I, pp. 217-272. JAI, Greenwich, CT.

Cavalier-Smith T. 1991c. Intron phylogeny: A new hypothesis. Trends Genet 7: 145-148.

Cavalier-Smith T. 1992. Origins of secondary metabolism. Ciba Found Symp 171: 64-80.

Cavalier-Smith T. 1993. Evolution of the eukaryotic genome. In The eukaryotic genome (ed. Broda P, et al.), pp. 333-385. Cambridge University Press, Cambridge.

Cavalier-Smith T. 1997. Cell and genome coevolution: Facultative anaerobiosis, glycosomes and kinetoplastan RNA editing. Trends Genet 13: 6-9.

Cavalier-Smith T. 1998. A revised six-kingdom system of life. Biol Rev Camb Philos Soc 73: 203-266.

Cavalier-Smith T. 2000. Membrane heredity and early chloroplast evolution. Trends Plant Sci 5: 174-182.

Cavalier-Smith T. 2001. Obcells as proto-organisms: Membrane heredity, lithophosphorylation, and the origins of the genetic code, the first cells, and photosynthesis. J Mol Evol 53: 555-595.

Cavalier-Smith T. 2002a. Meiosis. In The Oxford encyclopaedia of evolution, pp. 700-708. Oxford University Press, New York.

Cavalier-Smith T. 2002b. The neomuran origin of archaebacteria, the negibacterial root of the universal tree and bacterial megaclassification. Int J Syst Evol Microbiol 52: 7-76.

Cavalier-Smith T. 2002c. The phagotrophic origin of eukaryotes and phylogenetic classification of Protozoa. Int J Syst Evol Microbiol 52: 297-354.

Cavalier-Smith T. 2004. The membranome and membrane heredity in development and evolution. In Organelles, genomes and eukaryote phylogeny (ed. Hirt RP, Horner DS), pp. 335-351. CRC, Boca Raton, FL.

Cavalier-Smith T. 2005. Economy, speed and size matter: Evolutionary forces driving nuclear genome miniaturization and expansion. Ann Bot 95: 147-175.

Cavalier-Smith T. 2006a. Cell evolution and Earth history: Stasis and revolution. Philos Trans Roy Soc B 361: 9691006.

Cavalier-Smith T. 2006b. Origin of mitochondria by intracellular enslavement of a photosynthetic purple bacterium. Proc Roy Soc B 273: 1943-1952.

Cavalier-Smith T. 2006c. Rooting the tree of life by transition analysis. Biol Direct 1: 19.

Cavalier-Smith T. 2007a. Concept of a bacterium still valid in prokaryote debate. Nature 446: 7257.

Cavalier-Smith T. 2007b. The chimaeric origin of mitochondria: Photosynthetic cell enslavement, gene-transfer pressure, and compartmentation efficiency. In Origin of mitochondria and hydrogenosomes (ed. Martin WF, Müller M), pp. 161-199. Springer, Berlin.

Cavalier-Smith T. 2009. Predation and eukaryote cell origins: A coevolutionary perspective. Int J Biochem Cell Biol 41: $307-322$. 
The Neomuran Revolution and Origin of Eukaryotes

Cavalier-Smith T. 2010a. Deep phylogeny, ancestral groups, and the four ages of life. Philos Trans Roy Soc B 365: 111132.

Cavalier-Smith T. 2010b. Kingdoms Protozoa and Chromista and the eozoan root of eukaryotes. Biol Lett 6: 342-345.

Cavalier-Smith T. 2010c. Origin of the cell nucleus, mitosis and sex: Roles of intracellular coevolution. Biol Direct 5: 7.

Cavalier-Smith T. 2013a. Early evolution of eukaryote feeding modes, cell structural diversity, and classification of the protozoan phyla Loukozoa, Sulcozoa, and Choanozoa. Eur J Protistol 49: 115-178.

Cavalier-Smith T. 2013b. Symbiogenesis: Mechanisms, evolutionary consequences, and systematic implications. Ann Rev Eco Evol Syst 44: 145-172.

Cavalier-Smith T, Chao EE. 2012. Oxnerella micra sp. n. (Oxnerellidae fam. n.), a tiny naked centrohelid, and the diversity and evolution of Heliozoa. Protist 163: 574-601.

Cavalier-Smith T, Karpov SA. 2012. Paracercomonas kinetid ultrastructure, origins of the body plan of Cercomonadida, and cytoskeleton evolution in Cercozoa. Protist 163: $47-75$.

Cavalier-Smith T, Oates B. 2012. Ultrastructure of Allapsa vibrans and the body plan of Glissomonadida (Cercozoa). Protist 163: 165-187.

Cavalier-Smith T, Scoble JM. 2013. Phylogeny of Heterokonta: Incisomonas marina, a uniciliate gliding opalozoan related to Solenicola (Nanomonadea), and evidence that Actinophryida evolved from raphidophytes. Eur $J$ Protistol 49: 328-353.

Chalkia D, Nikolaidis N, Makalowski W, Klein J, Nei M. 2008. Origins and evolution of the formin multigene family that is involved in the formation of actin filaments. Mol Biol Evol 25: 2717-2733.

Ciccarelli FD, Doerks T, von Mering C, Creevey CJ, Snel B, Bork P. 2006. Toward automatic reconstruction of a highly resolved tree of life. Science 311: 1283-1287.

Csürös M, Miklós I. 2009. Streamlining and large ancestral genomes in Archaea inferred with a phylogenetic birthand-death model. Mol Biol Evol 26: 2087-2095.

Cubonova L, Sandman K, Hallam SJ, Delong EF, Reeve JN. 2005. Histones in crenarchaea. J Bacteriol 187: 54825485.

Dagan T, Roettger M, Bryant D, Martin W. 2010. Genome networks root the tree of life between prokaryotic domains. Genome Biol Evol 2: 379-392.

Dawes IW. 1981. Sporulation in evolution. In Cellular and molecular aspects of microbial evolution (ed. Carlile MJ, et al.), pp. 85-130. Cambridge University Press, Cambridge.

De Duve C, Wattiaux R. 1966. Functions of lysosomes. Ann Rev Physiol 28: 435-492.

Derelle R, Lang BF. 2012. Rooting the eukaryotic tree with mitochondrial and bacterial proteins. Mol Biol Evol 29: 1277-1289.

Desvaux M, Hebraud M, Talon R, Henderson IR. 2009. Secretion and subcellular localizations of bacterial proteins: A semantic awareness issue. Trends Microbiol 17: $139-145$.
Dippenaar-Schoeman AS, Jocqué R. 1997. African spiders: An identification manual. Agricultural Research Council, Pretoria, South Africa.

Dominguez-Cuevas P, Mercier R, Leaver M, Kawai Y, Errington J. 2012. The rod to L-form transition of Bacillus subtilis is limited by a requirement for the protoplast to escape from the cell wall sacculus. Mol Microbiol 83: 52-66.

Doolittle RF. 1995. The origins and evolution of eukaryotic proteins. Philos Trans R Soc Lond B 349: 235-240.

Doolittle WF. 2000. Uprooting the tree of life. Sci Am 282: 90-95.

Doolittle WF, Zhaxybayeva O. 2013. What is a prokaryote? In The prokaryotes-Prokaryotic biology and symbiotic association (ed. Rosenberg E, et al.), pp. 21-37. SpringerVerlag, Berlin.

Egan AJ, Vollmer W. 2013. The physiology of bacterial cell division. Ann NY Acad Sci 1277: 8-28.

Eichinger CS, Kurze A, Oliveira RA, Nasmyth K. 2013. Disengaging the Smc3/kleisin interface releases cohesin from Drosophila chromosomes during interphase and mitosis. EMBO J 32: 656-665.

Errington J. 2013. L-form bacteria, cell walls and the origins of life. Open Biol 3: 120143.

Ettema TJ, Bernander R. 2009. Cell division and the ESCRT complex: A surprise from the archaea. Commun Integr Biol 2: 86-88.

Faini M, Beck R, Wieland FT, Briggs JA. 2013. Vesicle coats: Structure, function, and general principles of assembly. Trends Cell Biol 23: 279-288.

Fan S, Whiteman EL, Hurd TW, McIntyre JC, Dishinger JF, Liu CJ, Martens JR, Verhey KJ, Sajjan U, Margolis B. 2011. Induction of Ran GTP drives ciliogenesis. Mol Biol Cell 22: $4539-4548$.

Feng DF, Cho G, Doolittle RF. 1997. Determining divergence times with a protein clock: Update and reevaluation. Proc Natl Acad Sci 94: 13028-13033.

Fournier GP, Gogarten JP. 2010. Rooting the ribosomal tree of life. Mol Biol Evol 27: 1792-1801.

Gabaldon T. 2010. Peroxisome diversity and evolution. Philos Trans R Soc Lond B 365: 765-773.

Gao B, Gupta RS. 2005. Conserved indels in protein sequences that are characteristic of the phylum Actinobacteria. Int J Syst Evol Microbiol 55: 2401-2412.

Gao B, Gupta RS. 2012. Phylogenetic framework and molecular signatures for the main clades of the phylum Actinobacteria. Microbiol Mol Biol Rev 76: 66-112.

Gao B, Paramanathan R, Gupta RS. 2006. Signature proteins that are distinctive characteristics of Actinobacteria and their subgroups. Antonie Van Leeuwenhoek 90: 69-91.

Gao B, Sugiman-Marangos S, Junop MS, Gupta RS. 2009. Structural and phylogenetic analysis of a conserved actinobacteria-specific protein (ASP1; SCO1997) from Streptomyces coelicolor. BMC Struct Biol 9: 40.

Garbarino JE, Gibbons IR. 2002. Expression and genomic analysis of midasin, a novel and highly conserved AAA protein distantly related to dynein. BMC Genomics 3: 18 .

Garcia Costas AM, Tsukatani Y, Romberger SP, Oostergetel GT, Boekema EJ, Golbeck JH, Bryant DA. 2011. Ultrastructural analysis and identification of envelope proteins 
T. Cavalier-Smith

of "Candidatus Chloracidobacterium thermophilum" chlorosomes. J Bacteriol 193: 6701-6711.

Geimer S, Melkonian M. 2005. Centrin scaffold in Chlamydomonas reinhardtii revealed by immunoelectron microscopy. Eukaryot Cell 4: 1253-1263.

Gluenz E, Povelones ML, Englund PT, Gull K. 2011. The kinetoplast duplication cycle in Trypanosoma brucei is orchestrated by cytoskeleton-mediated cell morphogenesis. Mol Cell Biol 31: 1012-1021.

Gogarten JP, Kibak H, Dittrich P, Taiz L, Bowman EJ, Bowman BJ, Manolson MF, Poole RJ, Date T, Oshima T, et al. 1989. Evolution of the vacuolar ATPase: implications for the origin of eukaryotes. Proc Natl Acad Sci 86: 66616665.

Gogendeau D, Hurbain I, Raposo G, Cohen J, Koll F, Basto R. 2011. Sas-4 proteins are required during basal body duplication in Paramecium. Mol Biol Cell 22: 1035-1044.

Grainge I, Lesterlin C, Sherratt DJ. 2011. Activation of XerCD-dif recombination by the FtsK DNA translocase. Nucleic Acids Res 39: 5140-5148.

Graur D, Martin W. 2004. Reading the entrails of chickens: Molecular timescales of evolution and the illusion of precision. Trends Genet 20: 80-86.

Gray MW. 1992. The endosymbiont hypothesis revisited. Int Rev Cytol 141: 233-357.

Gray MW, Doolittle WF. 1982. Has the endosymbiont hypothesis been proven? Microbiol Rev 46: 1-42.

Gribaldo S, Poole M, Daubin V, Forterre P, Brochier-Armanet C. 2010. The origin of eukaryotes and their relationship with the Archaea: Are we at a phylogenomic impasse? Nat Rev Microbiol 8: 743-752.

Gruber S, Errington J. 2009. Recruitment of condensin to replication origin regions by $\mathrm{ParB} / \mathrm{SpoOJ}$ promotes chromosome segregation in B. subtilis. Cell 137: 685-696.

Gualdrón-López M, Brennand A, Hannaert V, Quiñones W, Cáceres AJ, Bringaud F, Concepción JL, Michels PA. 2012. When, how and why glycolysis became compartmentalised in the Kinetoplastea. A new look at an ancient organelle. Int J Parasitol 42: 1-20.

Guichard P, Desfosses A, Maheshwari A, Hachet V, Dietrich C, Brune A, Ishikawa T, Sachse C, Gonczy P. 2012. Cartwheel architecture of Trichonympha basal body. Science 337: 553.

Gupta RS. 1998a. Life's third domain (Archaea): An established fact or an endangered paradigm? A new proposal for classification of organisms based on protein sequences and cell structure. Theor Popul Biol 54: 91-104.

Gupta RS. 1998b. Protein phylogenies and signature sequences: A reappraisal of evolutionary relationships among archaebacteria, eubacteria, and eukaryotes. Microbiol Mol Biol Rev 62: 1435-1491.

Gupta RS. 1998c. What are archaebacteria: Life's third domain or monoderm prokaryotes related to Gram-positive bacteria? A new proposal for the classification of prokaryotic organisms. Mol Microbiol 29: 695-708.

Gupta RS. 2011. Origin of diderm (Gram-negative) bacteria: Antibiotic selection pressure rather than endosymbiosis likely led to the evolution of bacterial cells with two membranes. Antonie Van Leeuwenhoek 100: 171-182.

Gupta RS. 2012. Origin and spread of photosynthesis based upon conserved sequence features in key bacteriochlor- ophyll biosynthesis proteins. Mol Biol Evol 29: $3397-$ 3412.

Guy L, Ettema TJ. 2011. The archaeal “TACK” superphylum and the origin of eukaryotes. Trends Microbiol 19: 580587.

Harashima H, Dissmeyer N, Schnittger A. 2013. Cell cycle control across the eukaryotic kingdom. Trends Cell Biol 23: $345-356$.

Harris JK, Kelley ST, Spiegelman GB, Pace NR. 2003. The genetic core of the universal ancestor. Genome Res 13: 407-412.

Heiss AA, Walker G, Simpson AG. 2013. The flagellar apparatus of Breviata anathema, a eukaryote without a clear supergroup affinity. Eur J Protistol 49: 354-372.

Heuser T, Raytchev M, Krell J, Porter ME, Nicastro D. 2009. The dynein regulatory complex is the nexin link and a major regulatory node in cilia and flagella. J Cell Biol 187: 921-933.

Heuser T, Barber CF, Lin J, Krell J, Rebesco M, Porter ME, Nicastro D. 2012. Cryoelectron tomography reveals doublet-specific structures and unique interactions in the I1 dynein. Proc Natl Acad Sci 109: E2067-E2076.

Hobel CF, Albers SV, Driessen AJ, Lupas AN. 2008. The Sulfolobus solfataricus AAA protein Sso0909, a homologue of the eukaryotic ESCRT Vps4 ATPase. Biochem Soc Trans 36: 94-98.

Idei M, Osada K, Sato S, Nakayama T, Nagumo T, Mann DG. 2013. Sperm ultrastructure in the diatoms Melosira and Thalassiosira and the significance of the $9+0$ configuration. Protoplasma 250: 833-850.

Ikeda T. 2008. Parkin-co-regulated gene (PACRG) product interacts with tubulin and microtubules. FEBS Lett 582: 1413-1418.

Ikeda K, Brown JA, Yagi T, Norrander JM, Hirono M, Eccleston E, Kamiya R, Linck RW. 2003. Rib72, a conserved protein associated with the ribbon compartment of flagellar A-microtubules and potentially involved in the linkage between outer doublet microtubules. $J$ Biol Chem 278: 7725-7734.

Ikeda K, Ikeda T, Morikawa K, Kamiya R. 2007. Axonemal localization of Chlamydomonas PACRG, a homologue of the human Parkin-coregulated gene product. Cell Motil Cytoskeleton 64: 814-821.

Iwabe N, Kuma K, Hasegawa M, Osawa S, Miyata T. 1989. Evolutionary relationship of archaebacteria, eubacteria, and eukaryotes inferred from phylogenetic trees of duplicated genes. Proc Natl Acad Sci 86: 9355-9359.

James TY, Pelin A, Bonen L, Ahrendt S, Sain D, Corradi N, Stajich JE. 2013. Shared signatures of parasitism and phylogenomics unite cryptomycota and microsporidia. Curr Biol 23: 1548-1553.

Javaux EJ, Knoll AH, Walter MR. 2001. Morphological and ecological complexity in early eukaryotic ecosystems. Nature 412: 66-69.

Jékely G. 2006. Did the last common ancestor have a biological membrane? Biol Direct 1: 35 .

Jékely G. 2008. Origin of the nucleus and Ran-dependent transport to safeguard ribosome biogenesis in a chimeric cell. Biol Direct 3: 31 . 
Jékely G, Arendt D. 2006. Evolution of intraflagellar transport from coated vesicles and autogenous origin of the eukaryotic cilium. BioEssays 28: 191-198.

Jerka-Dziadosz M, Gogendeau D, Klotz C, Cohen J, Beisson J, Koll F. 2010. Basal body duplication in Paramecium: The key role of Bld10 in assembly and stability of the cartwheel. Cytoskeleton (Hoboken) 67: 161-171.

John P, Whatley FR. 1975. Paracoccus denitrificans and the evolutionary origin of mitochondria. Nature 254: $495-$ 498.

John P, Whatley FR. 1977. Paracoccus denitrificans Davis (Micrococcus denitrificans Beijerinck) as a mitochondrion. Adv Bot Res 4: 51-115.

Kaimer C, Gonzalez-Pastor JE, Graumann PL. 2009. SpoIIIE and a novel type of DNA translocase, SftA, couple chromosome segregation with cell division in Bacillus subtilis. Mol Microbiol 74: 810-825.

Kee HL, Dishinger JF, Blasius TL, Liu CJ, Margolis B, Verhey KJ. 2012. A size-exclusion permeability barrier and nucleoporins characterize a ciliary pore complex that regulates transport into cilia. Nat Cell Biol 14: 431-437.

Keeling PJ. 2013. The number, speed, and impact of plastid endosymbioses in eukaryotic evolution. Annu Rev Plant Biol 64: 583-607.

Kressler D, Hurt E, Bergler H, Bassler J. 2012. The power of AAA-ATPases on the road of pre- 60 S ribosome maturation-Molecular machines that strip pre-ribosomal particles. Biochim Biophys Acta 1823: 92-100.

Lake JA, Skophammer RG, Herbold CW, Servin JA. 2009. Genome beginnings: Rooting the tree of life. Philos Trans R Soc Lond B 364: 2177-2185.

Lane N, Martin W. 2010. The energetics of genome complexity. Nature 467: 929-934.

Lasek-Nesselquist E, Gogarten JP. 2013. The effects of model choice and mitigating bias on the ribosomal tree of life. Mol Phylogenet Evol 69: 17-38.

Lechtreck KF, Brown JM, Sampaio JL, Craft JM, Shevchenko A, Evans JE, Witman GB. 2013. Cycling of the signaling protein phospholipase $\mathrm{D}$ through cilia requires the BBSome only for the export phase. J Cell Biol 201: 249261.

Li Z. 2012. Regulation of the cell division cycle in Trypanosoma brucei. Eukaryot Cell 11: 1180-1190.

Li S, Fernandez JJ, Marshall WF, Agard DA. 2012. Threedimensional structure of basal body triplet revealed by electron cryo-tomography. EMBO J 31: 552-562.

Lin J, Tritschler D, Song K, Barber CF, Cobb JS, Porter ME, Nicastro D. 2011. Building blocks of the nexin-dynein regulatory complex in Chlamydomonas flagella. J Biol Chem 286: 29175-29191.

Lin J, Heuser T, Song K, Fu X, Nicastro D. 2012. One of the nine doublet microtubules of eukaryotic flagella exhibits unique and partially conserved structures. PLOS ONE 7: e46494.

Livny J, Yamaichi Y, Waldor MK. 2007. Distribution of centromere-like parS sites in bacteria: Insights from comparative genomics. J Bacteriol 189: 8693-8703.

Lombard J, Moreira D. 2011. Origins and early evolution of the mevalonate pathway of isoprenoid biosynthesis in the three domains of life. Mol Biol Evol 28: 87-99.
Lombard J, López-García P, Moreira D. 2012a. An ACP-independent fatty acid synthesis pathway in archaea: Implications for the origin of phospholipids. Mol Biol Evol 29: $3261-3265$.

Lombard J, López-García P, Moreira D. 2012b. The early evolution of lipid membranes and the three domains of life. Nat Rev Microbiol 10: 507-515.

López-García P, Moreira D. 1999. Metabolic symbiosis at the origin of eukaryotes. Trends Biochem Sci 24: 88-93.

Löwe J, Amos LA. 2009. Evolution of cytomotive filaments: The cytoskeleton from prokaryotes to eukaryotes. Int Biochem Cell Biol 41: 323-329.

Makarova KS, Yutin N, Bell SD, Koonin EV. 2010. Evolution of diverse cell division and vesicle formation systems in Archaea. Nat Rev Microbiol 8: 731-741.

Marchandin H, Teyssier C, Campos J, Jean-Pierre H, Roger F, Gay B, Carlier JP, Jumas-Bilak E. 2010. Negativicoccus succinicivorans gen. nov., sp. nov., isolated from human clinical samples, emended description of the family Veillonellaceae and description of Negativicutes classis nov., Selenomonadales ord. nov. and Acidaminococcaceae fam. nov. in the bacterial phylum Firmicutes. Int J Syst Evol Microbiol 60: 1271-1279.

Margulis L. 1970. Origin of eukaryotic cells. Yale University Press, New Haven.

Martin W, Müller M. 1998. The hydrogen hypothesis for the first eukaryote. Nature 392: 37-44.

Martin W, Russell MJ. 2003. On the origins of cells: A hypothesis for the evolutionary transitions from abiotic geochemistry to chemoautotrophic prokaryotes, and from prokaryotes to nucleated cells. Philos Trans $R$ Soc Lond B 358: 59-85.

Matsuo K, Ohsumi K, Iwabuchi M, Kawamata T, Ono Y, Takahashi M. 2012. Kendrin is a novel substrate for separase involved in the licensing of centriole duplication. Curr Biol 22: 915-921.

Maupin-Furlow JA. 2013. Ubiquitin-like proteins and their roles in archaea. Trends Microbiol 21: 31-38.

Mizuno N, Taschner M, Engel BD, Lorentzen E. 2012. Structural studies of ciliary components. J Mol Biol 422: 163 180.

Nasmyth K. 1995. Evolution of the cell cycle. Philos Trans $R$ Soc Lond B 349: 271-281.

Nasmyth K. 2011. Cohesin: A catenase with separate entry and exit gates? Nat Cell Biol 13: 1170-1177.

Nather DJ, Rachel R. 2004. The outer membrane of the hyperthermophilic archaeon Ignicoccus: Dynamics, ultrastructure and composition. Biochem Soc Trans 32: 199-203.

Nicastro D, Fu X, Heuser T, Tso A, Porter ME, Linck RW. 2011. Cryo-electron tomography reveals conserved features of doublet microtubules in flagella. Proc Natl Acad Sci 108: E845-E853.

Norrander JM, deCathelineau AM, Brown JA, Porter ME, Linck RW. 2000. The Rib43a protein is associated with forming the specialized protofilament ribbons of flagellar microtubules in Chlamydomonas. Mol Biol Cell 11: 201215.

Novak B, Csikasz-Nagy A, Gyorffy B, Nasmyth K, Tyson JJ. 1998. Model scenarios for evolution of the eukaryotic cell cycle. Philos Trans R Soc Lond B 353: 2063-2076. 
T. Cavalier-Smith

Nunoura T, Takaki Y, Kakuta J, Nishi S, Sugahara J, Kazama H, Chee GJ, Hattori M, Kanai A, Atomi H, et al. 2011. Insights into the evolution of Archaea and eukaryotic protein modifier systems revealed by the genome of a novel archaeal group. Nucleic Acids Res 39: 3204-3223.

Oliveira RA, Nasmyth K. 2013. Cohesin cleavage is insufficient for centriole disengagement in Drosophila. Curr Biol 23: R601-R603.

Oliveira RA, Hamilton RS, Pauli A, Davis I, Nasmyth K. 2010. Cohesin cleavage and Cdk inhibition trigger formation of daughter nuclei. Nat Cell Biol 12: 185-192.

Ouhammouch M, Hausner W, Geiduschek EP. 2009. TBP domain symmetry in basal and activated archaeal transcription. Mol Microbiol 71: 123-131.

Pace NR. 2009. Mapping the tree of life: Progress and prospects. Microbiol Mol Biol Rev 73: 565-576.

Palmer T, Berks BC. 2012. The twin-arginine translocation (Tat) protein export pathway. Nat Rev Microbiol 10: 483 496.

Pan R, Hu J. 2011. The conserved fission complex on peroxisomes and mitochondria. Plant Signal Behav 6: 870-872.

Pearce MJ, Mintseris J, Ferreyra J, Gygi SP, Darwin KH. 2008. Ubiquitin-like protein involved in the proteasome pathway of Mycobacterium tuberculosis. Science 322: $1104-$ 1107.

Peretó J, López-García P, Moreira D. 2004. Ancestral lipid biosynthesis and early membrane evolution. Trends Biochem Sci 29: 469-477.

Petroff AP, Sim MS, Maslov A, Krupenin M, Rothman DH, Bosak T. 2010. Biophysical basis for the geometry of conical stromatolites. Proc Natl Acad Sci 107: 9956-9961.

Pieuchot L, Jedd G. 2012. Peroxisome assembly and functional diversity in eukaryotic microorganisms. Annu Rev Microbiol 66: 237-263.

Pigino G, Geimer S, Lanzavecchia S, Paccagnini E, Cantele F, Diener DR, Rosenbaum JL, Lupetti P. 2009. Electrontomographic analysis of intraflagellar transport particle trains in situ. J Cell Biol 187: 135-148.

Podar M, Makarova KS, Graham DE, Wolf YI, Koonin EV, Reysenbach AL. 2013. Insights into archaeal evolution and symbiosis from the genomes of a nanoarchaeon and its inferred crenarchaeal host from Obsidian Pool, Yellowstone National Park. Biol Direct 8: 9.

Reeve JN, Bailey KA, Li WT, Marc F, Sandman K, Soares DJ. 2004. Archaeal histones: structures, stability and DNA binding. Biochem Soc Trans 32: 227-230.

Rucktäschel R, Halbach A, Girzalsky W, Rottensteiner H, Erdmann R. 2010. De novo synthesis of peroxisomes upon mitochondrial targeting of Pex3p. Eur J Cell Biol 89: 947-954.

Samson RY, Obita T, Freund SM, Williams RL, Bell SD. 2008. A role for the ESCRT system in cell division in archaea. Science 322: 1710-1713.

Sandoval-Calderón M, Geiger O, Guan Z, Barona-Gómez F, Sohlenkamp C. 2009. A eukaryote-like cardiolipin synthase is present in Streptomyces coelicolor and in most actinobacteria. J Biol Chem 284: 17383-17390.

Santarella-Mellwig R, Pruggnaller S, Roos N, Mattaj IW, Devos DP. 2013. Three-dimensional reconstruction of bacteria with a complex endomembrane system. PLoS Biol 11: e1001565.
Satir P, Mitchell DR, Jekely G. 2008. How did the cilium evolve? Curr Top Dev Biol 85: 63-82.

Schirrmeister BE, de Vos JM, Antonelli A, Bagheri HC. 2013. Evolution of multicellularity coincided with increased diversification of cyanobacteria and the Great Oxidation Event. Proc Natl Acad Sci 110: 1791-1796.

Servin JA, Herbold CW, Skophammer RG, Lake JA. 2008. Evidence excluding the root of the tree of life from the actinobacteria. Mol Biol Evol 25: 1-4.

Sherratt DJ, Arciszewska LK, Crozat E, Graham JE, Grainge I. 2010. The Escherichia coli DNA translocase FtsK. Biochem Soc Trans 38: 395-398.

Shavit L, Penny D, Hendy MD, Holland BR. 2007. The problem of rooting rapid radiations. Mol Biol Evol 24: 2400-2411.

Silhavy TJ, Kahne D, Walker S. 2010. The bacterial cell envelope. Cold Spring Harb Perspect Biol 2: a000414.

Skophammer RG, Herbold CW, Rivera MC, Servin JA, Lake JA. 2006. Evidence that the root of the tree of life is not within the Archaea. Mol Biol Evol 23: 1648-1651.

Skophammer RG, Servin JA, Herbold CW, Lake JA. 2007. Evidence for a Gram-positive, eubacterial root of the tree of life. Mol Biol Evol 24: 1761-1768.

Smirnov A, Chao EE, Nassonova E, Cavalier-Smith T. 2011. A revised classification of naked lobose amoebae (Amoebozoa: Lobosa). Protist 162: 545-570.

Song H, Sandie R, Wang Y, Andrade-Navarro MA, Niederweis M. 2008. Identification of outer membrane proteins of Mycobacterium tuberculosis. Tuberculosis (Edinb) 88: 526-544.

Sousa FL, Shavit-Grievink L, Allen JF, Martin WF. 2013. Chlorophyll biosynthesis gene evolution indicates photosystem gene duplication, not photosystem merger, at the origin of oxygenic photosynthesis. Genome Biol Evol 5: $200-216$.

Stanier RY. 1970. Some aspects of the biology of cells and their possible evolutionary significance. In Organization and control in prokaryotic and eukaryotic cells (Society for General Microbiology Symposium 20) (ed. Charles HP, Knigh JG), pp. 1-38. Cambridge University Press, Cambridge.

Stouf M, Meile JC, Cornet F. 2013. FtsK actively segregates sister chromosomes in Escherichia coli. Proc Natl Acad Sci 110: $11157-11162$.

Sullivan NL, Marquis KA, Rudner DZ. 2009. Recruitment of SMC by ParB-parS organizes the origin region and promotes efficient chromosome segregation. Cell 137: 697 707.

Sutcliffe IC. 2010. A phylum level perspective on bacterial cell envelope architecture. Trends Microbiol 18: 464-470.

Sutcliffe IC. 2011. Cell envelope architecture in the Chloroflexi: A shifting frontline in a phylogenetic turf war. Environ Microbiol 13: 279-282.

Thiergart T, Landan G, Schenk M, Dagan T, Martin WF. 2012. An evolutionary network of genes present in the eukaryote common ancestor polls genomes on eukaryotic and mitochondrial origin. Genome Biol Evol 4: 466-485.

Tsukatani Y, Romberger SP, Golbeck JH, Bryant DA. 2012. Isolation and characterization of homodimeric type-I reaction center complex from Candidatus Chloracidobacterium thermophilum, an aerobic chlorophototroph J Biol Chem 287: 5720-5732. 
The Neomuran Revolution and Origin of Eukaryotes

Tyson JJ, Novak B. 2008. Temporal organization of the cell cycle. Curr Biol 18: R759-R768.

Valas RE, Bourne PE. 2009. Structural analysis of polarizing indels: An emerging consensus on the root of the tree of life. Biol Direct 4: 30.

Valas RE, Bourne PE. 2011. The origin of a derived superkingdom: How a Gram-positive bacterium crossed the desert to become an archaeon. Biol Direct 6: 16.

van Dam TJ, Townsend MJ, Turk M, Schlessinger A, Sali A, Field MC, Huynen MA. 2013. Evolution of modular intraflagellar transport from a coatomer-like progenitor. Proc Natl Acad Sci 110: 6943-6948.

Van Valen LM, Maiorana VC. 1980. The archaebacteria and eukaryotic origins. Nature 287: 248-250.

Verhey KJ, Dishinger J, Kee HL. 2011. Kinesin motors and primary cilia. Biochem Soc Trans 39: 1120-1125.

Vossbrinck CR, Maddox JV, Friedman S, Debrunner-Vossbrinck BA, Woese CR. 1987. Ribosomal RNA sequence suggests microsporidia are extremely ancient eukaryotes. Nature 326: 411-414.

Ward NL, Challacombe JF, Janssen PH, Henrissat B, Coutinho PM, Wu M, Xie G, Haft DH, Sait M, Badger J, et al 2009. Three genomes from the phylum Acidobacteria provide insight into the lifestyles of these microorganisms in soils. Appl Environ Microbiol 75: 2046-2056.

Wickstead B, Gull K. 2011. The evolution of the cytoskeleton. J Cell Biol 194: 513-525.

Wickstead B, Gull K, Richards TA. 2010. Patterns of kinesin evolution reveal a complex ancestral eukaryote with a multifunctional cytoskeleton. BMC Evol Biol 10: 110.

Williams TA, Embley TM. 2014. Archaeal “dark matter” and the origin of eukaryotes. Genome Biol Evol 6: 474-481.

Williams TA, Foster PG, Nye TM, Cox CJ, Embley TM. 2012. A congruent phylogenomic signal places eukaryotes within the Archaea. Proc Biol Sci 279: 4870-4879.

Williams TA, Foster PG, Cox CJ, Embley TM. 2013. An archaeal origin of eukaryotes supports only two primary domains of life. Nature 504: 231-236.
Woese CR. 1994. There must be a prokaryote somewhere: microbiology's search for itself. Microbiol Rev 58: 1-9.

Woese CR. 2013. How we do, don't, and should look at bacteria and bacteriology. In The prokaryotes: Prokaryotic biology and symbiotic associations (ed. Rosenberg E, et al.), pp. 3-20. Springer, New York.

Woese CR, Fox GE. 1977. Phylogenetic structure of the prokaryotic domain: The primary kingdoms. Proc Natl Acad Sci 74: 5088-5090.

Woese CR, Kandler O, Wheelis ML. 1990. Towards a natural system of organisms: Proposal for the domains Archaea, Bacteria, and Eucarya. Proc Natl Acad Sci 87: 4576-4579.

Wolf YI, Makarova KS, Yutin N, Koonin EV. 2012. Updated clusters of orthologous genes for Archaea: A complex ancestor of the Archaea and the byways of horizontal gene transfer. Biol Direct 7: 46.

Yang Z. 2007. Fair-balance paradox, star-tree paradox, and Bayesian phylogenetics. Mol Biol Evol 24: 1639-1655.

Yutin N, Makarova KS, Mekhedov SL, Wolf YI, Koonin EV. 2008. The deep archaeal roots of eukaryotes. Mol Biol Evol 25: 1619-1630.

Yutin N, Wolf MY, Wolf YI, Koonin EV. 2009. The origins of phagocytosis and eukaryogenesis. Biol Direct 4: 9.

Yuzawa Y, Nishihara H, Haraguchi T, Masuda S, Shimojima M, Shimoyama A, Yuasa H, Okada N, Ohta H. 2012. Phylogeny of galactolipid synthase homologs together with their enzymatic analyses revealed a possible origin and divergence time for photosynthetic membrane biogenesis. DNA Res 19: 91-102.

Zhang Z, Green BR, Cavalier-Smith T. 2000. Phylogeny of ultra-rapidly evolving dinoflagellate chloroplast genes: A possible common origin for sporozoan and dinoflagellate plastids. J Mol Evol 51: 26-40.

Zhao S, Shalchian-Tabrizi K, Klaveness D. 2013. Sulcozoa revealed as a paraphyletic group in mitochondrial phylogenomics. Mol Phylogenet Evol 69: 462-468.

Zhaxybayeva O, Lapierre P, Gogarten JP. 2005. Ancient gene duplications and the root(s) of the tree of life. Protoplasma 227: 53-64. 


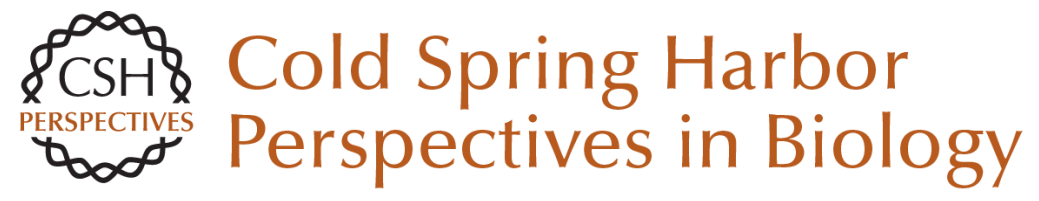

\section{The Neomuran Revolution and Phagotrophic Origin of Eukaryotes and Cilia in the Light of Intracellular Coevolution and a Revised Tree of Life}

Thomas Cavalier-Smith

Cold Spring Harb Perspect Biol 2014; doi: 10.1101/cshperspect.a016006

Subject Collection The Origin and Evolution of Eukaryotes

The Persistent Contributions of RNA to

Eukaryotic Gen(om)e Architecture and Cellular

Function

Jürgen Brosius

Green Algae and the Origins of Multicellularity in the Plant Kingdom

James G. Umen

The Archaeal Legacy of Eukaryotes: A

Phylogenomic Perspective

Lionel Guy, Jimmy H. Saw and Thijs J.G. Ettema

Origin and Evolution of the Self-Organizing

Cytoskeleton in the Network of Eukaryotic

Organelles

Gáspár Jékely

On the Age of Eukaryotes: Evaluating Evidence from Fossils and Molecular Clocks

Laura Eme, Susan C. Sharpe, Matthew W. Brown, et al.

Origin of Spliceosomal Introns and Alternative Splicing

Manuel Irimia and Scott William Roy
Eukaryotic Origins: How and When Was the

Mitochondrion Acquired?

Anthony M. Poole and Simonetta Gribaldo

Bacterial Influences on Animal Origins

Rosanna A. Alegado and Nicole King

Missing Pieces of an Ancient Puzzle: Evolution of the Eukaryotic Membrane-Trafficking System Alexander Schlacht, Emily K. Herman, Mary J. Klute, et al.

The Neomuran Revolution and Phagotrophic Origin of Eukaryotes and Cilia in the Light of Intracellular Coevolution and a Revised Tree of Life

Thomas Cavalier-Smith

Protein Targeting and Transport as a Necessary

Consequence of Increased Cellular Complexity

Maik S. Sommer and Enrico Schleiff

How Natural a Kind Is "Eukaryote?"

W. Ford Doolittle

For additional articles in this collection, see http://cshperspectives.cshlp.org/cgi/collection/

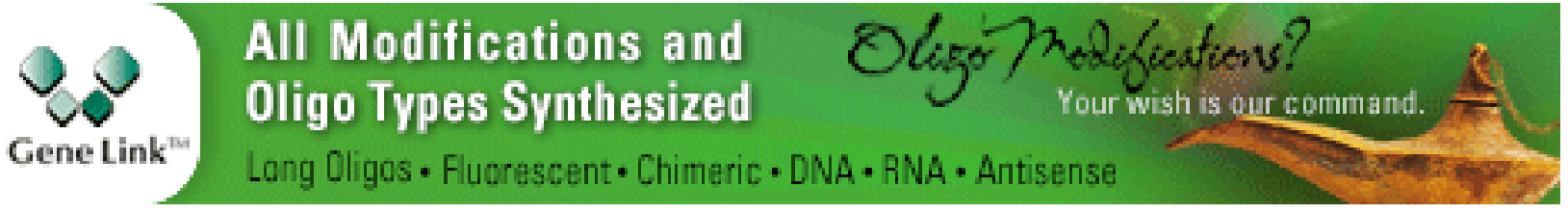


Protein and DNA Modifications: Evolutionary Imprints of Bacterial Biochemical Diversification and Geochemistry on the Provenance of Eukaryotic Epigenetics

L. Aravind, A. Maxwell Burroughs, Dapeng Zhang, et al.

The Eukaryotic Tree of Life from a Global Phylogenomic Perspective Fabien Burki
What Was the Real Contribution of

Endosymbionts to the Eukaryotic Nucleus?

Insights from Photosynthetic Eukaryotes David Moreira and Philippe Deschamps

Bioenergetic Constraints on the Evolution of Complex Life

Nick Lane

For additional articles in this collection, see http://cshperspectives.cshlp.org/cgi/collection/

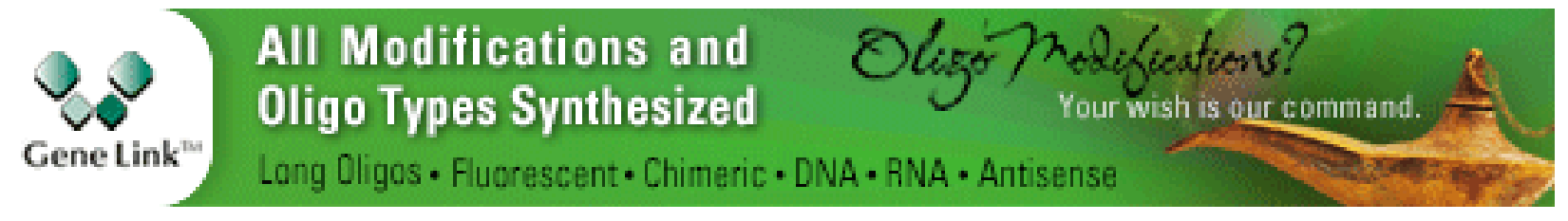

Copyright @ 2014 Cold Spring Harbor Laboratory Press; all rights reserved 